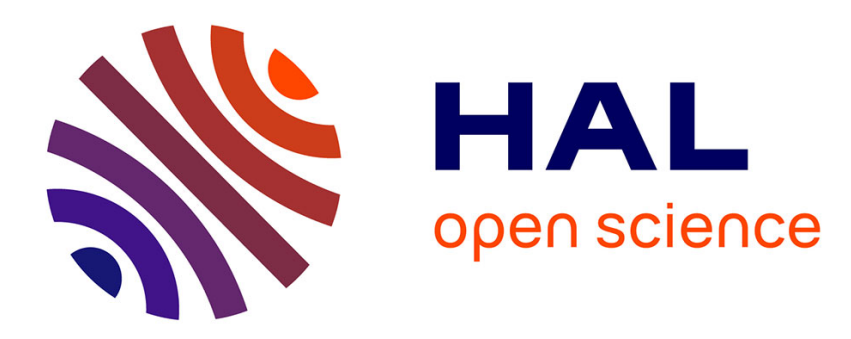

\title{
Crisis, Capital Controls and Covered Interest Parity: Evidence from China in Transformation
}

\author{
Jinzhao Chen
}

\section{To cite this version:}

Jinzhao Chen. Crisis, Capital Controls and Covered Interest Parity: Evidence from China in Transformation. 2012. halshs-00660654

\section{HAL Id: halshs-00660654 \\ https://shs.hal.science/halshs-00660654}

Preprint submitted on 17 Jan 2012

HAL is a multi-disciplinary open access archive for the deposit and dissemination of scientific research documents, whether they are published or not. The documents may come from teaching and research institutions in France or abroad, or from public or private research centers.
L'archive ouverte pluridisciplinaire HAL, est destinée au dépôt et à la diffusion de documents scientifiques de niveau recherche, publiés ou non, émanant des établissements d'enseignement et de recherche français ou étrangers, des laboratoires publics ou privés. 


\section{PARISSCHOQL OF ECQNOMICS}

WORKING PAPER N²012 - 01

Crisis, Capital Controls and Covered Interest Parity: Evidence from China in Transformation

Jinzhao Chen

JEL Codes: C32, F21, F31, F32

Keywords: Covered Interest Parity, Capital Control, China, Threshold Autoregressive model, GARCH effect, Financial Crisis

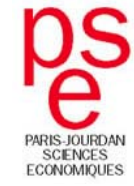




\title{
Crisis, Capital Controls and Covered Interest Parity: Evidence from China in Transformation*
}

\author{
Jinzhao CHEN $^{\dagger}$ \\ Paris School of Economics
}

Version 3: October 3, 2011

\begin{abstract}
This paper aims to investigate the intensity and the effectiveness of the capital controls in China from 2003 to 2010, with special attention to the period of financial turbulence that erupted in the summer of 2007. We employ a two-regime threshold autoregressive model to study the Renminbi yield differential between the onshore interest rate and its non-deliverable forward (NDF)-implied offshore interest rate. We find that the de facto intensity of capital controls measured by the threshold increases over time, even during the period of financial turbulence. Moreover, a slightly lower speed of adjustment to the threshold implies that the capital controls are effective in this context.
\end{abstract}

Keywords: Covered Interest Parity; Capital Control; China; Threshold Autoregressive model; GARCH effect, Financial Crisis.

JEL Classification: C32, F21, F32.

\footnotetext{
${ }^{*}$ This work was supported by Ile-de-France. Part of the paper was written when the author was Ph.D candidate at University of Paris Nanterre and was research assistant at CEPII research center where the valuable comments and help of Director Agnès Bénassy-Quéré are gratefully acknowledged. A preliminary version of this research was circulated and presented as "Effectiveness of Capital Controls in China: Evidence from Covered Interest Parity and Capital Flows". The author thanks Michel Aglietta, Jung-Hyun Ahn, Régis Breton, Bertrand Gobillard, Anne-Laure Delatte and Yamina Tadjeddine, especially Vincent Bignon, for their valuable and detailed comments. I am also grateful to Sophie Béreau for her suggestion for an earlier version, to Raphaelle Bellando, Bertrand Blancheton, Changsheng Chen, Chia-Shang James Chu, Gilbert Colletaz, Jin-Chuan Duan, Eric Girardin, Jean-Yves Gnabo, Bruce E. Hansen, Pierre-Cyrille Hautcoeur, Sébastien Laurent, David G. Mayes, Nikolay Nenovsky and Wing Thye Woo for helpful comments and discussions. I thank participants of the CERC-CCER Conference "Finance and Economic Performance in China" (Sigtuna, June 2009), University of Paris West Doctoral seminar (Nanterre, June 2009), the 7th International Conference on the Chinese Economy (Clermont-Ferrand, October 2009), the LEO seminar of University Orléans, the 27th Symposium on Money, Banking and Finance organized by University of Montesquieu-Bordeaux IV (Bordeaux, June 2010), the Workshop on Econometrics and Financial Studies after Crisis organized by Institute of Economics, Academia Sinica (June, 2010), the 21st annual conference of CEA (UK) and the 2nd annual conference of CEA (Europe) held at the University of Oxford (Oxford, July 2010), the 19th Symposium of the Society for Nonlinear Dynamics and Econometrics (SNDE) held at George Washington University (Washington D.C., March 2011); the CEPN seminar of University of Paris-Nord 13 (Villetaneuse, March 2011), the CEPII seminar (Paris, May 2011), North American Summer Meeting of the Econometric Society (St. Louis, June 2011), the Venice Summer Institute Workshop on The Evolving Role of China in the Global Economy organized by CESifo and Venice International University (San Servolo, July 2010). Xingwang Qian is acknowledged for proving some forward exchange rate datasets. I also thank Alessandro Rebucci for detailed discussion, Bertrand Candelon, Yin-Wong Cheung, Menzie Chinn, Guonan Ma, Robert McCauley, Tara Sinclair for constructive suggestions. I thank anonymous referees for their valuable comments. The usual disclaimer applies.

${ }^{\dagger}$ E-mail: jichen@pse.ens.fr.
} 


\section{Introduction}

During the East-Asia financial crisis of 1997, China's relatively closed capital accounts were considered by some commentators to be an important element in its ability to maintain a stable exchange rate (IMF, 2000) and in preventing it from suffering harmful effects. Twelve years later, while most European countries were experiencing the downturn triggered by the financial crisis of 2007, China and the developing countries of the East Asia-Pacific region were the first to recover from the global crisis, and it is likely that they will grow rapidly during the next decade.

To sustain their brisk economic recovery and make global growth benefit from Asian growth, the public debate and discussions underscore the fact that capital controls limiting capital inflows (or swings in hot monies searching for higher-yielding assets) may avoid the potential overheating and bubble formation in these emerging economies. That is important since large and sudden capital movements can pose a risk to their economies and financial systems and stem the sustainability of economic recovery. Under this circumstance, it is interesting to note how China coped with this financial turmoil and the implied economic slowdown. To this end, it is especially important to not look at the de jure capital controls but at their impact through an assessment of their effectiveness.

Thus, we aim to investigate the intensity and the effectiveness of the capital controls in China from 2003 to 2010, with special attention to the period of financial turbulence that erupted in the summer of 2007. The evidence is based on the covered interest parity (CIP), with the measuring of the Renminbi (RMB) yield differential between the onshore interest rate and its non-deliverable forward (NDF)-implied offshore interest rate. A special feature of this paper is that we employed a two-regime threshold autoregressive model to study the RMB yield differential, with the estimated thresholds determined by the intensity of controls on capital inflows and transaction costs. An increase of the threshold indicates the strengthening of the de facto capital control intensity; a lower speed of adjustment to the threshold implies a more effective capital control, whereas a higher speed means either less effectiveness or a more integrated market.

Another feature of this paper is that we divided the sample into three sub-periods to examine the effects of the Chinese exchange rate reform in 2005 and the recent global financial turbulence, with more attention to the latter. The financial crisis highlighted the pivotal role of the US dollar and gave rise to an acute dollar shortage, more acute than that of the 1950s (Cheung et al., 2010). As for its effects on China and other Asian countries, one feature is the stronger deviations from CIP and accompanied volatility. But what is less known is that the financial crisis interrupted the experiment of managing a gradual strengthening of RMB against trading partners' currencies (Ma and McCauley, 2010). The resulting relinkage to the dollar would hinder the RMB's internationalization (Cheung et al., 2010), which itself could serve to break the dependence of the international financial system on a currency subject to national management. In this circumstance, the investigation of the capital controls of China and its monetary policy during this sub-period is needed.

This paper is organized as follows: in the next section, we present the capital controls adopted in China. In section 3, main studies and methods related to covered interest parity 
are briefly reviewed. In section 4, we discuss the empirical methodologies adopted: the measuring of RMB yield differential between onshore and offshore market, and the threshold autoregressive model with conditional variance. Section 5 involves the data. In section 6 the results of estimation and hypothesis testing are presented and discussed. The final section concludes.

\section{Capital controls in China}

As for the implementation of capital controls in China, the "all-included" foreign exchange management system was replaced and transformed into a government-administrated control regime over transactions and currency exchanges in capital accounts. ${ }^{1}$ Long-run capital inflows are generally welcomed, while China maintains controls on both short-term capital inflows and outflows, focusing more on the regulation of the volatility of capital flows rather than their volumes. Quantitative and regulatory controls are implemented on the exchange between the RMB and foreign currencies. The evolving restrictions on the financial account have three aspects: the management of foreign direct investments, the controls over international portfolio investment, and controls over foreign debts. Their implementation involves two forms of management (Zhang, 2003). First, most cross-border capital transactions need to be approved by the relevant government departments, e.g., the Peoples Bank of China, or regulatory authorities like the China Securities Regulatory Commission (CSRC). The Qualified Foreign Institutional Investor (QFII) program issued in 2002, the Qualified Domestic Institutional Investor (QDII) program started in 2006 and its further extensions issued in 2007 and 2008 have greatly relaxed the restrictions on access by foreign investors to domestic financial markets and by Chinese investors to oversea financial markets. The second form of capital management lies in the controls imposed by the State Administration of Foreign Exchange (SAFE) on foreign exchange transactions related to relevant capital transactions, such as the repatriation of foreign currency-denominated funding raised overseas by domestic companies, cross-border remittance. The strengthened supervision in 2008 on the balance of payments by SAFE mainly takes this form, and it aims to prevent the entry of hot money via the channels of trade, such as FDI and RMB-denominated accounts of non-residents. In summation, Chinas controls are a direct restriction on cross-border capital flows, based mainly on administrative approval and quantitative limitation.

\section{What can we learn from the covered interest parity about capital controls: A brief review}

The covered interest parity (CIP) condition - i.e. the nullity of the covered interest differential - is an unalloyed criterion to judge "capital mobility" in the sense of the extent of financial market integration across national boundaries. ${ }^{2}$ Accordingly, CIP is widely recognized as

\footnotetext{
${ }^{1}$ The first offcial appearance of the term "foreign exchange in capital accounts" was in the "Regulations on the Foreign Exchange System of the People's Republic of China" promulgated in 1996.

${ }^{2}$ Other methods defining capital mobility includes Feldstein-Horioka definition (Feldstein and Horioka, 1980), real interest parity, uncovered interest parity (Frankel, 1992, 1993).
} 
the most appropriate indicator of the degree of the financial integration across countries (Frankel, 1992; Holmes and Wu, 1997; Holmes, 2001) and the indicator of capital controls; for example, these controls have been found to interfere with the achievement of CIP in Germany between 1970 and 1974 (Dooley and Isard, 1980) and in Japan in the 1970s (Otani and Tiwari, 1981; Ito, 1987).

According to CIP, the interest differential between two assets, identical in every aspect except currency of denomination, should be zero once allowance is made for currency hedging. Deviations from the CIP condition would reflect transaction costs in a broad sense (Frankel, 1992). ${ }^{3}$ For non-comparable assets (i.e., assets issued in different political jurisdictions), as concluded by Aliber (1973) in his seminal paper, political risk accounts for much of the observed differential. In the latest financial turbulence, Baba and Packer (2009) rationalize the deviation from CIP with the counterparty risk and the liquidity risk. Here we focus on the determinants of the deviation associated with capital controls.

There are few studies in the literature about the evidence of CIP in China. The principal reason lies in the fact that neither a liquid onshore forward exchange market nor the eurocurrency market of RMB exists before 2005. In this circumstance, the difference between RMB's onshore interest rate and its offshore counterpart cannot be measured directly, as Dooley and Isard (1980) did for German Mark; neither could it be done indirectly for the difference of the arbitrage gains, as Ito (1987) devised for the Japanese Yen. ${ }^{4}$ Nevertheless, with the implicit assumption that the covered interest parity condition holds for RMB in the offshore financial market, Ma and McCauley (2008) have calculated the yield differentials between the onshore interest rate of RMB and its offshore counterpart implied by CIP. By comparing these rates between two markets, where different regimes of capital controls exist, the interest rate differential is a quantitative indicator of the effect of capital controls. They have also shown that, even though these differentials have been shrinking over time, especially after abandoning the peg to USD in July 2005, capital controls in China are still binding, as these interest rate differentials remain large and allow the Chinese government to retain a short-term monetary autonomy to some extent. However, their data sample does not include the recent period of turbulence. The soar and the slump of the yield differential cannot be simply explained by the effectiveness or powerlessness of the capital controls. In this context, further quantitative modeling seems necessary, and via this mean, we aim to fill the gap and shed some light on the efficacy of China's capital controls.

\footnotetext{
${ }^{3}$ The literature has attempted to rationalize departure from CIP in terms of transactions costs (Branson, 1969; Frenkel and Levich, 1975, 1977); capital market imperfection (Prachowny, 1970; Frenkel, 1973); capital controls (Otani and Tiwari, 1981; Frankel, 1993); data imperfection or mismatch (Taylor, 1989, 1987).

${ }^{4}$ In 1970s, Japan had separated markets under different capital control regimes. The arbitrage gains derived from CIP in the offshore market represent only the transaction costs, while those derived on the onshore market are associated with the transaction costs and capital controls in place.
} 


\section{Methodology}

\subsection{Quantifying the interest yield differential from covered interest parity}

The covered parity condition holds only if the international capital movements are free from capital controls. The ratio of the forward exchange rate to the spot rate is then equal to the ratio of the domestic interest yield against that of its foreign counterpart:

$$
\frac{F}{S}=\frac{1+R}{1+R^{F}}
$$

where $F$ is the forward rate for a given maturity, $S$ is the spot rate (domestic price of the foreign currency), $R$ is the nominal interest rate of the home currency, and $R^{F}$ is the foreign interest rate. When capital controls bind, non-residents may not have full access to the onshore monetary market; also, when an onshore forward exchange market does not exist or the existing one is not well developed, non-residents cannot make use of the forward exchange contracts to cover the exchange rate risk exposure of their onshore portfolios, giving rise to the non-deliverable forward (NDF) contract. ${ }^{5}$ With this financial instrument, a gain equivalent to that of euro-currency deposit - which does not exist for most of the countries having offshore NDF markets - can be obtained. Assuming that the offshore NDF market, which is considered as a benchmark market, is very active and the CIP holds there, we have

$$
\frac{N D F}{S}=\frac{1+i}{1+R^{F}}
$$

where $i$ is the NDF-implied yield of the home currency offshore. To the extend that the arbitrage between the onshore money market and the offshore NDF market is effectively constrained by capital controls, the NDF-implied offshore interest rate, $i$, can differ considerably from the interest rate prevailing on the onshore money market, $R$. This yield differential (or spread) can be written as

$$
Y=\frac{1+R}{1+i}=\frac{(1+R) S}{N D F\left(1+R^{F}\right)}
$$

A large and persistent onshore/offshore spread $y$ indicates the presence of effective crossborder restrictions. ${ }^{6}$ Moreover, a yield gap bigger than 1 implies appreciation pressures on

\footnotetext{
${ }^{5}$ Like standard forward contracts, NDF contracts fix exchange rates for a future date. However, there is no delivery of the underlying foreign currency as in forward contracts. Instead, the net US dollar is settled with a compensating payment made or due based upon the difference between the NDF contract rate and the exchange rate prevailing at maturity. For more information about the NDF contracts, refer to the Foreign Exchange Committee website (http://www.newyorkfed.org/fxc/) and the EMTA website (http://www.emta.org/). For recent developments of Asian NDF markets and specifically that of RMB NDF market, see Ma et al. (2004), Fung et al. (2004) and Peng et al. (2007).

${ }^{6}$ Alternative way to investigate the effect of capital controls is to calculate the price differential of RMB exchange rate from covered interest parity, that is, assume that RMB has same interest rate in both the onshore and the offshore markets. If the CIP holds in the offshore market, we can derive an offshore spot exchange rate (with equation (1)) which should be equal to the quoted rate in the domestic market. A eventual persistent difference of this rate implies the segmented foreign exchange market due to the bindingness of capitals controls or deviation of currency from its current equilibrium level. In fact, this approach aims to verify the law of one price for the external value of the RMB, while we focus on the difference of its interest
} 
the home currency in the presence of capital controls and vice versa.

If we assume that, on the offshore market, the CIP does not hold for some reasons (discussed in section 6) and there exists a deviation from this parity, we write this deviation as $\pi$, and rewrite equation (2):

$$
\begin{aligned}
& 1+\pi=\frac{S}{N D F} \times \frac{1+i}{1+R^{F}} \\
& Y^{\prime}=\frac{1+R}{1+i}=\frac{(1+R) S}{(1+\pi) N D F\left(1+R^{F}\right)}
\end{aligned}
$$

We write equation (5) in linear form and have:

$$
y^{\prime}=\underbrace{R+s-R^{F}-n d f}_{y}-\underbrace{\pi}_{\text {latentfactor }}
$$

where $y^{\prime}$ (or $y$ ), $s$ and $n d f$ is the logarithm of $Y^{\prime}$ (or $Y$ ), $S$ and $N D F$ respectively. $y^{\prime}$ consists of two parts: the yield differentials ( $y$ ) defined in Ma and McCauley (2008), which represents capital controls and transaction costs, and some latent factor $\pi$ resulting in the deviation from CIP on the offshore market. $y^{\prime}$ is our variable of interest and it is the yield differential even when the CIP does not hold in the offshore market. However, $y^{\prime}$ is not observable because of latent factor $\pi$. Thus we calculate $y$ and obtain $y^{\prime}$ using a technique discussed later.

As to the empirical approaches relevant to the deviation from CIP and consistent with our question, this paper considers only the univariate analysis that studies the behavior and the dynamics of $y^{\prime} .{ }^{7}$ Within this branch, three mains methods can be distinguished: the first relies on computing actual deviations from interest parity (e.g., Frenkel and Levich, 1975), and the second involves the stationary or unit root analysis of the deviation from CIP (e.g., Holmes, 2001). In this case, the speed with which deviations from CIP are eliminated is an indicator of the effectiveness of capital controls and the extent of financial integration between different countries. ${ }^{8}$ A more recent approach consists of assuming and testing the behaviors of deviation from CIP based on the regime (or space) they lie in by means of estimating a threshold autoregressive model that we will present next (e.g., Peel and Taylor, 2002; Taylor and Tchernykh-Branson, 2004). ${ }^{9}$

\subsection{Threshold Autoregressive (TAR) model}

The TAR model was first proposed by Tong (1978) and further developed by Tong and Lim (1980) and Tong (1983). It is motivated by several commonly observed nonlinear charac-

\footnotetext{
yield.

${ }^{7}$ (see, e.g., Taylor and Tchernykh-Branson, 2004; MacDonald, 2007) for the multivariate regression analysis.

${ }^{8}$ Higher convergence speed implies a quicker convergence to CIP and hence tighter financial integration.

${ }^{9}$ By estimating a band-TAR model, Peel and Taylor (2002) have supported the conjecture of Keynes and Einzig (Keynes, 1923; Einzig, 1937) that deviations from CIP in the interwar period did not tend to be arbitraged at all until they were of the order of fifty basis points.
} 
teristics such as asymmetry in declining and rising patterns of a process, limit cycles of a cyclical time series. ${ }^{10}$

A special (or restricted) case of TAR, called the Band-TAR model, was first applied by Obstfeld and Taylor (1997) for testing the theory of purchasing power parity and the nonlinear adjustment of price. ${ }^{11}$ It has also been employed to investigate the validity of CIP by taking into account arbitrage costs in the financial market (e.g., Peel and Taylor, 2002; Taylor and Tchernykh-Branson, 2004). ${ }^{12}$ The presence of fixed costs does not allow the agents to adjust continually their positions. Within the band implied by the transaction costs, the agent will not arbitrage, as the CIP would not apply: the deviation from CIP follows a random walk. Outside the band, unexploited profit triggers arbitrage which reverts the deviation from CIP to the edge of the band, with this process characterized by an autoregressive model (AR(1), for example). A simple version of such Band-TAR model may be written as:

$$
\Delta y_{t}= \begin{cases}\rho^{\text {out }}\left(y_{t-1}-c^{\text {up }}\right)+\epsilon_{t}^{\text {out }} & \text { if } \quad y_{t-1}>c^{\text {up }} \\ \rho^{\text {in }} y_{t-1}+\epsilon_{t}^{\text {in }} & \text { if } \quad c^{\text {low }} \leq y_{t-1} \leq c^{u p} \\ \rho^{\text {out }}\left(y_{t-1}-c^{\text {low }}\right)+\epsilon_{t}^{\text {out }} & \text { if } \quad y_{t-1}<c^{\text {low }}\end{cases}
$$

where $c^{\text {up }}\left(c^{\text {low }}\right)$ is the upper (lower) threshold; $\epsilon_{t}^{\text {out }}$ is $N\left(0, \sigma^{\text {out }}{ }^{2}\right), \epsilon_{t}^{\text {in }}$ is $N\left(0, \sigma^{\text {in }}{ }^{2}\right)$, here $\rho^{\text {in }}$ could be restricted to zero, and $\rho^{\text {out }}$ is the convergence speed outside the thresholds of arbitrage (or inaction).

The TAR model outlined above has three regimes and two thresholds. However, when the theory is not specific about the complete structure of the model, the number of regimes (or thresholds) in the model cannot be assumed to be known a priori. As our specification is supported by the transaction cost theory, the assumption of such a band-TAR model offers a simple interpretation of the results. ${ }^{13}$ Hutchison et al. (2009) use this three-regime TAR model to investigate capital control liberalization in India. Nevertheless, we apply some formal tests to confirm this hypothesis of nonlinearity or even further the number of thresholds if the linearity is rejected. ${ }^{14}$

As shown in Figure 3, there are insufficient data points during the sample period that will pass through the lower threshold, which is supposed to be negative. This is explained by the pressure exerted by capital inflows to China and by the corresponding bindingness of capital controls. Therefore, we cannot identify the asymmetric band TAR model outlined above. Nevertheless, Taylor and Tchernykh-Branson (2004) point out that this is the case in most

\footnotetext{
${ }^{10}$ For a brief discussion of the theoretical and empirical motivations of this class of model, see, e.g.,Hansen (1999).

${ }^{11}$ A standard model with transportation costs implies that real exchange rates should follow a band threshold model in which the process is a random walk within the band and a mean reversion outside it.

${ }^{12}$ To test the law of one price and to shed some light on the international financial integration, Levy Yeyati et al. (2009) estimate an augmented Band-TAR model with generalized autoregressive conditional heteroskedastic (GARCH) effect for the cross-market premium of the stock price.

${ }^{13} \mathrm{~A}$ non-arbitrage band exists for small deviations from the CIP. The upper and the lower thresholds are determined by intensity of the capital controls and transaction costs.

${ }^{14}$ Tsay (1989) proposed a graphical approach for locating the values of the thresholds and the number of the regimes. Alternatively, Hansen (1999) has generalized the sup-LR test and sequential least squares estimations to the SETAR models with more than two regimes.
} 
emerging markets, which lead consequently to the specification of a single upper threshold model (e.g., Figure 2). ${ }^{15}$ We follow this approach and write the model of the form: ${ }^{16}$

$$
\Delta y_{t}= \begin{cases}\rho^{\text {out }}\left(y_{t-1}-c^{u p}\right)+\epsilon_{t}^{\text {out }} & \text { if } y_{t-1}>c^{u p} \\ \epsilon_{t}^{\text {in }} & \text { if } y_{t-1} \leq c^{u p}\end{cases}
$$

When $c^{u p}$ is known, simple least-squares methods can be applied to each subset of the data partitioned by the single threshold. In the absence of prior knowledge about the threshold, we can still estimate this model via a grid search of all possible values of the threshold variable (here $y_{t-1}$ ), which either minimizes the sum of squared residuals or maximizes the log-likelihood function of the model. ${ }^{17}$ For correcting the autocorrelation and the heteroskedasticity prevalent in the residual, we refine the model by adding the lag(s) of the dependent variable and the GARCH effect, as in Levy Yeyati et al. (2009), and rewriting it as

$$
\begin{aligned}
\Delta y_{t} & =1_{\text {out }} \rho^{\text {out }}\left(y_{t-1}-c^{u p}\right)+1_{\text {in }}\left(\rho^{\text {in }} y_{t-1}+C^{\text {in }}\right)+\sum_{j=1}^{k} \phi_{j} \Delta y_{t-j}+\epsilon_{t} \\
\sigma_{t}^{2} & =\alpha_{0}+\sum_{j=1}^{p} \alpha_{j} \epsilon_{t-j}^{2}+\sum_{j=1}^{q} \lambda_{j} \sigma_{t-j}^{2}
\end{aligned}
$$

where $1_{\text {in }}\left(1_{\text {out }}\right)$ is the indicator function and is equal to 1 when $y_{t-1}<c^{u p}\left(y_{t-1} \geq c^{u p}\right)$ and 0 otherwise, $C^{i n}$ is the constant term in the inner regime. In this specified TAR $(2, \mathrm{k}, \mathrm{d})$ model, 2 is the number of regimes, $k$ is the augmented lag length, and $d$ is the delay parameter. As we will detail later, we divide our sample into three sub-periods, as the structural change and the outbreak of the financial crisis are represented in our data, and we set $k$ to 0 or 1 to correct for the autocorrelation in the residuals. Due to the lack of a precise theoretical prior about the delay parameter $d$, we set it to 1 for all sub-samples, following on this the existing studies (e.g. Bec et al., 2004; Bec and Ben Salem, 2004). ${ }^{18} \rho^{\text {in }}$ and $\rho^{\text {out }}$ represent the convergence speed in the no-arbitrage and arbitrage regime, respectively. ${ }^{19}$ Moreover, we assume the same error terms and conditional variance for both of the two regimes. ${ }^{20}$

\footnotetext{
${ }^{15}$ They estimate a single-threshold model for the deviation from the CIP of Thai baht, Indonesian rupiah, Philippine peso, Singapore dollar, Korean won and Taiwan dollar, with the covered interest arbitrage involving the arbitrage along the term structure.

${ }^{16}$ Once the data allow with longer time span, the asymmetric band-TAR model could be estimated in the same way, by adding another dimension in the grid search of the thresholds that we discuss later in this subsection.

${ }^{17}$ When the threshold variable for the grid search is the lagged value of the dependent variable with delay $d$ (here $d=1$ ), the TAR model is called self-exciting TAR or SETAR. See Mignon and Dufrénot (2004) for an application of the SETAR to the French consumption and its determinants. The Band-TAR model estimated in this paper is an extended SETAR model with some restrictions. We simply use TAR hereafter.

${ }^{18}$ Based on their simulation, Bec and Ben Salem (2004) pointed out that the estimator of this parameter is particularly unreliable for the series showing a certain degree of persistence.

${ }^{19}$ If the estimated coefficient of $\rho^{\text {in }}$ is not significant (as we expected according to the assumption that the yield differentials follow a random walk within the band), we can estimate a restricted model by imposing this coefficient to zero.

${ }^{20}$ In other words, here we assume that the threshold effect exists only in the mean equation. See, e.g., Obstfeld and Taylor (1997); Taylor and Tchernykh-Branson (2004) for the cases in which the variance is assumed different for each regime; and Glosten et al. (1993) for a threshold (or asymmetric) volatility (GARCH) model. Another extension is to relax the assumption of same error terms and same conditional variance in the
} 
The number of ARCH and GARCH terms ( $p$ and $q$ ) could be specified differently for each sub-sample. Generally, a GARCH $(1,1)$ is sufficient for each sub-sample to take into account the heteroskedasticity. ${ }^{21}$

We estimate the outlined model by following the procedure described in Obstfeld and Taylor (1997): by a grid search - for the potential threshold - on all values of the threshold variable, we estimate the TAR model with the threshold which maximizes the log likelihood ratio $L L R=2\left(L_{a}-L_{n}\right)$, in which $L_{a}\left(L_{n}\right)$ is the log likelihood of the alternative TAR model (null AR model). ${ }^{22}$ The likelihood function of the above TAR can be written as

$$
L_{a}\left(\rho^{\text {out }}, \rho^{i n}, \sigma^{2}, c^{u p}, C^{i n}\right)=-\frac{1}{2} \sum_{t}\left[\ln \left(\sigma^{2}\right)+\epsilon_{t}^{2} / \sigma^{2}\right]
$$

Once the TAR model is estimated, we can run a threshold test as a test of specification for checking the adequacy of the TAR alternative relative to the AR null. Because the threshold is not defined under the null, the LLR does not follow the standard $\chi^{2}$ distribution, and the standard inference is invalid. One way to resolve this problem is to use the Monte Carlo simulation to derive the critical value of the LLR test (e.g., Obstfeld and Taylor, 1997; Hansen, 1999): estimate and fit an AR (1) null model with GARCH effect on the actual data $\left(y_{1}, \cdots, y_{T}\right)$. With estimated parameters, we simulate the fitted linear model. ${ }^{23} \mathrm{We}$ then estimate the TAR model for each simulated series and calculate the corresponding LLR. The empirical distribution of the LLR is then tabulated and used as an inference to judge the alternative TAR model against the AR null. However, this method suffers from the tail heaviness of the residuals which violate the hypothesis of normally distributed residual assumed in the aforementioned Monte Carlo simulation; consequently, the LLR test may have low power. ${ }^{24}$

\section{Data}

Our sample for computing the yield differential spans from May 6th, 2003 to December 12, 2010. The short span of the sample is dictated by the availability of the data. The onshore-offshore Chinese currency (RMB) yield differential is derived from the RMB spot rate, the 3-month RMB NDF rate, the 3-month US dollar LIBOR rate and the 3-month PBOC (People's Bank of China: Central Bank of China) bill rate (proxy of the onshore

\footnotetext{
different regimes, and to specify a model with threshold effect in both the mean and the variance equations.

${ }^{21}$ Generally, lower orders such as $(1,1),(1,2)$ and $(2,1)$ are adopted in applications since higher orders models are difficult to estimate and to interpret.

${ }^{22}$ Maximizing this ratio equals the maximization of the $\log$ likelihood function of the TAR alternative mentioned earlier. To ensure an adequate number of observations on each side of the threshold (or in each threshold space), here we exclude the highest $15 \%$ and the lowest $15 \%$ values of the threshold variable from the grid search, as widely implemented in practice.

${ }^{23}$ For example, 600 simulations are generated for the fitted model. We start each simulation with $y_{-b}=0$, end at $y_{T}$, and then discard the first $b$ (set to 50) to avoid the initial value bias.

${ }^{24}$ Hansen (1999) provides an alternative simulation approach based on bootstrap, instead of supposing other possible forms of distribution, such as the Student-t distribution, the Generalized Error distribution (GED) and the skewed-Student distribution. However, simulate with bootstrapping an augmented AR(1) model with GARCH effect complicates the traditional Monte Carlo procedure and is very time-consuming. Hence, we leave it for the future research, and simply use, in this paper, the test of specification based on the simulation aforementioned, with caution when the TAR alternative is rejected.
} 
interest rate). ${ }^{25}$ Datasets used for calculation, estimation and hypothesis testing are of daily frequency and extracted from Datastream and Bloomberg.

Despite the relatively short sample span, it is possible to have some structural breaks or dramatic policy changes during the entire period, particularly the global crisis of 2007 . Actually, we divide the whole sample into three sub-samples as follows: the first period (5/06/2003-7/20/2005), the second (7/21/2005-8/8/2007) and the third (8/9/2007-2/12/2010), based principally on the historical events that may have an impact on the monetary or foreign exchange policy. Two eventual structural changes are documented in the literature. The first event was the reform of the Chinese exchange rate regime taken into effect in July 2005, which ended the peg of RMB to USD and created a managed float based on a basket of currencies. ${ }^{26}$ The second one was the recent financial turmoil triggered in August 2007, with August 8 considered as the timing of the break (e.g., Taylor and Williams, 2008a,b; Baba and Packer, 2009). We implement the hypothesis testing and the estimation on these sub-periods, respectively. ${ }^{27}$ Furthermore, with the test of Lee and Strazicich (2003), which can identify the structural changes and at the same time test for stationarity, we compare these dates with our ex ante choices.

\section{Empirical Results}

The yield differentials are calculated based on the equation (5) for the 3 month maturity and plotted in Figure 3 for the whole period. The substantial and persistent RMB yield differential may indicate large transactions costs and imply that the capital controls are effective. ${ }^{28}$ As for the speed of reversion to "equilibrium", we rely on a TAR model with upper threshold as described above. Before presenting the results of estimation, some preliminary analysis is implemented.

\subsection{Unit Root (UR) Analysis}

If the yield differentials have a unit root, this indicates that the deviations are persistent and not mean reverting, which implies that capital controls are effective enough to maintain a gap between the onshore and the offshore RMB interest rate. In contrast, the stationary characteristics represent a process of returning to the equilibrium level, via the activity of arbitrage in the market. Furthermore, the speed of the convergence can be calculated by estimating the autoregressive parameter of the stationary process validated. A relatively low speed can still imply the binding control on capital flows. However, high-speed meanreversion may indicate the ineffectiveness of capital controls or a higher degree of financial market integration.

\footnotetext{
${ }^{25}$ For the reason why these proxies are chosen and for a detailed description of their characteristics, see, e.g., Ma and McCauley (2008). Data for the PBOC bill rate are only available from May 6th, 2003.

${ }^{26}$ However, several authors have doubts about the real effect of this change (see, e.g., Goldstein and Lardy, 2006; Shah et al., 2005).

${ }^{27}$ By distinguishing three sub-periods based on the breaks in the vehicle of American monetary policy, Bec and Ben Salem (2004) test the unit root and apply a threshold error correction model to the interest rate term spread for both the whole period and each sub-period.

${ }^{28}$ Table 1 summarizes the means and the t-statistics of the measured yield differentials for different subperiods.
} 
Following the traditional practice in the literature, non-stationarity check is executed before specifying the linear (or nonlinear) characteristic of the series. However, standard UR tests are known to be biased toward the non-rejection of a unit root when they are applied to time series with non-linear dynamics. ${ }^{29}$ Numerous UR tests with various hypotheses of non-linearity can be used to increase the power of the UR test. Here, we only apply the generalized least squares (GLS) UR test (NP test hereafter) of Ng and Perron (2001) and the Momentum-TAR test of Enders and Granger (1998), which assumes a M-TAR model in the alternative. Our statistical inferences are mainly based on the latter, whereas the former is for comparison. ${ }^{30}$

The two UR tests are applied to the whole sample and to each sub-sample, with the results reported in Table 2. Not surprisingly, for the whole sample, both lead to the rejection of the UR null, as the tests become biased because of the structural changes. To adequately model and carefully investigate the series of the yield differentials, we also apply these two tests to each sub-sample. The results do not always provide the same evidence; the NP test cannot reject the UR null for any of the three sub-periods (see Table 2), implying the absence of the mean reversion of the yield differential, while the M-TAR test only accepts the UR for the third sub-period. Based on the results of M-TAR test during the first two sub-periods, the yield differentials are stationary but nonlinear. As to the third one (the period the financial turbulence), even with the same conclusion of the two tests, we accept the non-stationarity of the yield differential with caution. ${ }^{31}$ The reason for this violation of the interest rate parity is still unclear: is it induced by the liquidity risk or the strengthening of the capital controls or even both? We provide an answer at the end of this section.

Finally, the UR test proposed by Lee and Strazicich (2003)(LS test hereafter) is used to identify the structural changes. Their minimum Lagrange multiplier unit root test endogenously determines the location of (up to) two structural breaks in level and/or in trend, and tests the null of a unit root, without diverging in the presence of breaks under the null. ${ }^{32}$ The results are shown in Table 3; for the timing of the structural breaks, the first one basically corresponds to the date of the exchange rate regime reform, whereas the second one fails to confirm the advent of the financial crisis. Because the timing of the breaks may be data dependent, we keep our dates of breaks exogenously determined under the guidance of historical facts. As for the result of the unit root of the LS test, the fact that the null cannot be rejected is possibly due to the aforementioned low power of the test when the

\footnotetext{
${ }^{29}$ For the discussion on the low power of the traditional unit root tests in the presence of asymmetric adjustment, see, e.g., Enders and Granger (1998).

${ }^{30}$ Using Monte Carlo experiment, Choi and Moh (2007) showed that the M-TAR test and the Inf $-t$ test due to Park and Shintani (2005) outperform the others, and that they have reasonable power of discerning the unit root.

${ }^{31}$ The results of Choi and Moh (2007) also indicate that the often claimed "unit-root first, nonlinearity second" approach will be of reduced merit when the associated AR parameters take large values. Since this makes challenging for the extant technical devices to detect the stationarity of the processes with high AR parameter, regardless of their nonlinearity. They suggest that what determines the power of unit root tests is not the specific type of nonlinearity in the alternative model, but how far the alternative model is away from the unit root process. The procedure proposed by Harvey and Leybourne (2007) provides an alternative for testing the linearity before checking the UR.

${ }^{32}$ Alternatively, Hutchison et al. (2009) employ the method suggested by Bai and Perron (1998) to detect the structural changes. We do not adopt this approach because of the technical constraint on the sample size (less than 500 observations) of their GAUSS code.
} 
non-linearity is not specified in the alternative. ${ }^{33}$

\subsection{AR vs.TAR}

Although the TAR model has theoretical support, it is nevertheless worth searching for its empirical support by testing the existence of threshold-type nonlinearity before its estimation. Can linearity be rejected? Even in that case, is the outlined TAR model well specified? The result of M-TAR does not give a clear-cut answer, as the rejection of the unit root null does not imply that the real data definitely follow the process of M-TAR, notably because the non-linear alternative could be misspecified. To answer these questions, we apply several widely used linearity tests: the F-test of Tsay (1989), the sup-LM test of Hansen (1996), and our simulation-based log likelihood ratio test (LLR test) as the tests of specification for the TAR model. ${ }^{34}$

For the first two ready-to-wear tests, fitting an AR (k) model ( $n$ is the $n^{\text {th }}$ of lags) for each sub-sample is needed to assure that the residuals contain no serial correlation. Then, these two tests are applied to the residuals; the results are reported in Table 5. Tsay's test rejects the linearity only for the corrected series of third period, and Hansen's test only for the first period. We provide two main possible explanations for this failure of non-rejecting the linear null: first, these two tests assume homoskedastic errors, which are evidently not the case for our samples. Second, failing to reject the linearity may be explained by the non-stationarity of volatility of the specified linear model, that is, the sum of $\alpha_{1}$ and $\lambda_{1}$ superior to 1 (see the coefficients of variance equation reported in Table 4$),{ }^{35}$ because the non-stationarity of volatility may affect the consistency, convergence rates and asymptotic distributions of the coefficients. ${ }^{36}$ Turning on our LLR test, the linearity is rejected at $5 \%$ but only for the first sub-period (see LLR test in Table 5). ${ }^{37}$ In view of the absence of the unanimous rejection of linearity, the presence of non-stationarity volatility in the linear autoregressive model, and the low power of the simulation-based LLR test for discerning the competing models, we focus on the specified TAR model and compare with its linear counterpart for a balanced interpretation.

Following the method described in subsection 4.2, we estimate the threshold and the TAR model using the same specification as the AR-GARCH model. When some estimated coefficients are not significant, we impose some restrictions on the fitted models and reestimate them. The results are reported in Table 6 .

\footnotetext{
${ }^{33}$ The construction of an UR test with the nonlinear alternative capable of detecting the structural breaks is expected for the future study, which is out of scope of this paper.

${ }^{34}$ For a comparison and an application of the two former linearity tests, see Ben Salem and Perraudin (2001).

${ }^{35}$ Petrucelli and Woolford (1984) show that the necessary and sufficient conditions for the stationarity of $\delta y_{t-1}$ is: $\rho^{\text {in }}<0, \rho^{\text {out }}<0$ and $\left(1+\rho^{\text {in }}\right)\left(1+\rho^{\text {out }}\right)<0$ for any value of $c$. In our case, the ARCH and the GARCH effect are significant for all sub-samples, while the volatility is stationary only in the second sub-sample.

${ }^{36}$ However, $\mathrm{Xu}$ (2008) proved that the non-stationary volatility generally changes the convergence rates of the trend estimates to the true values and may lead to inconsistent estimation, while those of the autoregressive slope estimates are not penalized.

${ }^{37}$ As discussed in 4.2 , because of the low power of LLR test, the probability with which the TAR model is mistakenly rejected is high.
} 


\subsection{CIP before September 2007}

Here we discuss the results of the estimation for each sub-period. The estimated upper threshold indicates the de facto extent of capital controls, and the autoregressive parameter measures the speed of convergence to the zero-profit point under the force of arbitrage. Before the abandonment of the dollar peg of RMB in July 2005, the threshold estimated is about 200 base points, which approximates its unconditional mean (367 points, see Table 1), and it indicates the extent of capital controls and pure transaction costs. Below the threshold, the yield differential follows a random walk and reverts to it under the force of the arbitrage when it lies above the threshold but with a low speed (half life of 36 days). The AR model reports a shorter HL of 21 days. Both of them show a long HL of mean reversion and a non-stationary volatility (the sum of $\alpha_{1}$ and $\lambda_{1}$ is bigger than 1), allowing us to conclude on the market segmentation and the effectiveness of the capital controls. The non-stationary volatility is possibly due to the short period of the data. In other words, as the mean-reversion is long, the conditional variance does not end the reverting cycle during the short time of the first sub-period. ${ }^{38}$ Actually, since 2002, the expectation of the revaluation has been reinforced, along with the leap of current account surplus and the accumulation of the US dollar as the foreign exchange reserve, and the forward premium has increased gradually. However, the dollar peg was well maintained until the reform. ${ }^{39}$ Meanwhile, the evolution of the RMB interest rate (PBOC bill rate) did not follow, and it even runs in the opposite direction to the US Libor, indicating an autonomy of monetary policy (see Figure 5). In this context, the fixed exchange rate regime is maintained through the effective restrictions on cross-border capital flows, which are represented by the persistent and volatile yield differential.

After the introduction of the new managed float regime in July 2005, the threshold estimated by the TAR model, contrary to what was expected, increased to about 270 base points, even exceeding its reduced unconditional mean. Nevertheless, a half life (HL) of only 3 days indicates a more unified and active monetary and exchange market where the unexploited profits are quickly reduced by arbitrage to the threshold once the yield differential exceeds it. In contrast to the TAR model, the linear AR reports a longer HL (about 14 days), which is still lower compared to the one of the first sub-period. The significant constant term in the differenced mean equation indicates a positive trend in the level of the yield differential. It means that the extent of the de facto capital control increases over time. Moreover, even if the conditional variance persists, the volatility becomes stationary according to both models, providing more evidence of the increased liquidity of this market.

Here we provide some possible explanations for the increased threshold and the far shorter HL. On the one hand, the higher threshold implies that during this sub-period capital controls are still binding and that the extent of the controls is even strengthened. This is mainly due to some policy measures introduced later in this sub-period targeting the short-term cross-

\footnotetext{
${ }^{38}$ The author acknowledges Jin-Chuan Duan for this point. The short sample is due to the data availability of the PBOC bill rate. When we use China Interbank Offered Rate (Chibor) as the proxy of onshore interest rate, we obtain the stationary volatility. Since the central bank bill rate is more liquid and a better proxy for the onshore interest rate than the Chibor, we keep using this rate to estimate our TAR model for all three sub-periods.

${ }^{39}$ See Ma and McCauley (2010) for the evidence.
} 
border financial activities; one such measure is the guideline issued by SAFE in October 2006 on restricting mainland entities' participation in NDF market. This is in response to the participation of some mainland entities, mainly corporations for hedging purpose, in arbitrage between markets. This result is consistent with the explanation that for the initial episode of the new regime, considered a transitional phase, the narrowing of the onshore and offshore RMB yield differential is a chosen policy outcome rather than as the waning effectiveness of the capital controls interpreted by market observers (see Ma and McCauley, 2008), which is used to interpret the much lowered unconditional mean after the regime change. On the other hand, the quick mean-reverting process (or a shorter HL) implies that once the unexploited profit appears and exceeds the transaction costs and risk associated with capital controls, the active arbitrage funds take swift action, despite binding capital controls. This action reduces quickly the yield differential to the level of the threshold.

There is a considerable but well-managed appreciation of RMB against the dollar and a clear co-movement between the NDF and the spot rate during this period. However, what is less known is that it was managed against a basket of trading partner currencies, with a moderate $(2 \%$ per annum) upward crawling and within narrow $( \pm 2 \%)$ bands (Ma and McCauley, 2010). ${ }^{40}$ Meanwhile, a persistent and sizable gap between the RMB onshore rate and the US Libor rate has been maintained, in spite of the similar trends, suggesting that Chinese monetary authorities could still use independent domestic policy in an effort to prevent the economy from overheating and curb accelerating inflation. The PBOC has increased the lending rates five times during this period. All of these facts in 2007 corroborate the effectiveness of capital controls.

\subsection{Capital controls since financial crisis}

Entering into a period of turbulence, the upward and downward spirals of the yield differential could not be fully explained by the eventual strengthening of capital controls implemented by the Chinese government. A look at both the countries with high financial integration (Figure 1) and some Asian economies with NDF markets (Figure 2 and Table 7) reveals some common factor(s) which can explain the abnormal behavior of the yield differentials.

For those major currencies, the appearance and even the persistence of deviation from CIP during periods of uncertainty and turmoil are not a recent story (e.g., Taylor, 1989). However, the liquidity risk caused by the US dollar funding shortage of non-US institutions and the significantly increased counterparty risk have been documented as the main reasons for the deviation of CIP in the recent turmoil. Furthermore, the dollar Libor has been reported to have underestimated the funding costs that European financial institutions actually faced, as the measurement error of the true dollar funding costs over the period could have increased and therefore been misleading (e.g., Baba et al., 2008; Baba and Packer, 2009). ${ }^{41}$

\footnotetext{
${ }^{40}$ The period of this stable managed float regime spans from June 2006 to May 2008.

${ }^{41}$ Because of perceived heightening of counterparty risk and their own increased demand for dollar liquidity, the US financial institutions were reluctant to lend dollars to their non-US counterparts, making the interbank market dried up. Thus European banks took the foreign exchange swap market as the important source of US dollar funding for matching their sharply increased dollar assets. Even the FX swaps can be viewed as effectively collateralized transactions, the collateral does not cover the entire counterparty risk, which will be added as premia to the elevated cost of raising dollars.
} 
After the bankruptcy of Lehman Brothers, the dollar liquidity problem for European banks deepened and translated into a phenomenon of global dollar shortage.

In this context, the impact of the financial turmoil on the evolution of yield differentials can be represented by a few latent common factors mentioned above, especially the liquidity risk (e.g., Baba and Packer, 2009; Levy Yeyati et al., 2009; Fong et al., 2010). Here we use factor analysis based on a principal component approach to estimate this latent factor for six Asian economies active on the NDF market. ${ }^{4243}$ The results are reported in Table 8 and Table $9 .{ }^{44}$ We then regress the raw data of yield differential of the third period over the first factor index, which measures the increased liquidity risk associated with the financial crisis. The residual of this common factor is the "deflated series", with which the alternative model is estimated and the hypothesis testing is implemented.

These corrected yield differentials are plotted in Figure 3, accompanied by the raw series of the whole sample. Its volatility (the standard deviation) is halved compared to the original data (see also the last row of Table 1), but still higher than the first two sub-periods. During the period of turbulence, the yield differentials are mean reverting, as shown in the results of the UR tests (see last row of Table 2). An HL of about 10 days (shorter than in the second sub-period) estimated by the linear AR model confirms this result, even though this model reports a non-stationary volatility (see Table 4). In contrast with the model estimated using the original data of the period of turmoil, the HL are much shorter once the volatility is deflated. In other words, when the dollar funding shortage triggers the lack of liquidity; the liquidity risk premium incurs extra volatility, makes the mean-reverting process much slower and consequently creates the illusion that the longer HL reflects tighter and more effective capital controls, which may not exist. Therefore, the comparison between the HL estimated with raw series and that of corrected series shows that the longer HL induced by liquidity risk or some other factor during the period of turbulence makes the interpretation of HL by the effectiveness of the capital controls insufficient and misleading.

Our TAR model results show an increase in the threshold to 315 basis points (see Table 6) while the HL (about 4 days) is slightly extended, indicating that the extent of the de facto capital control has been strengthened during the crisis. For instance, in August 2008, the issued regulation requires companies with FDI to submit the certified reports of their capital denominated in foreign currency, aiming to limit the inflows of "hot money" via the aforementioned FDI channels. As for the HL, estimated either by AR or TAR model, it changes only slightly relative to that of the second sub-period, implying that the markets are more and gradually integrated with the advent of new currency regime, even if they were

\footnotetext{
${ }^{42}$ In the offshore markets like Hong Kong and Singapore where the Asian NDF transactions are highly active, there are less conterparty risk since the NDF contracts do not entail currency delivery of the notional amounts at the maturity.

${ }^{43}$ Alternative way to estimate the latent common factor is to use a dynamic factor model based on Kalman filtering, and this could be an extension of this paper.

${ }^{44}$ Two common factors are retained (bold face figures in upper panel of Table 8) based on Kaiser criterion which drops all components with eigenvalues less than 1. Varimax rotation is then used to differentiate the original variables by extracted factor. Each factor will tend to have either large or small loadings of any particular variable, in our case the first factor (we assume it as the liquidity risk) has large positive loadings on twd, inr, and cny (see lower panel of Table 8). We restart the factor analysis only on these three variables, and obtain the index of this first common factor (see Table 9).
} 
partly affected by the financial turbulence.

In fact, with the eruption of financial turmoil and the continual dollar depreciation against most major currencies (see Figure 4), there has been more Western short-term capital pursuing high earnings flow into emerging Asian markets, causing the appreciation of these Asian currencies, and the expectation of a further and more rapid appreciation of the RMB than what the spot rate actually had. This increases the forward discount. Afterward, there is even expectation of depreciation at the end of 2008 when the PBOC return to the dollar peg as a special measure during the financial turmoil. The fluctuation of NDF makes the forward premium and consequently the RMB yield differential volatile.

In the monetary market, the interest gap was reduced (middle panel of Figure 5) to the proximity of interest rate parity after the failure of Lehman Brothers. To attenuate the shock on the domestic economy and stimulate the domestic consumption, the Chinese monetary authority has adopted an expansionary monetary policy, decreasing the benchmark deposit and lending rate five times and the deposit reserve requirement ratio four times since September 2008 (until October 2010). This is in line with the purpose of the US Federal Reserve to provide the liquidity to the market. The introduction of the RMB currency swap market in August 2008 and that of the foreign exchange dealer system into the interbank foreign exchange market in October of the same year can be interpreted as a commitment of the Chinese government to further develop and deepen the foreign exchange market and to increase the liquidity of the associated derivatives market, which is an important condition to facilitate the outward foreign investment and to compensate the inflows of hot money. This could explain the rapid reversion to the threshold when excessive profit emerged in the market. Since the quick recovery of Chinese economic growth, the interest rate was moderately adjusted upward, resulting in a persistent gap with the US Libor. In sum, with this evidence, we witness that during the financial turmoil the de facto intensification of capital controls translated into an increased threshold. We also find that the effectiveness of the capital controls, as the speed of adjustment (the HL) was slightly reduced. However, in spite of this slower adjustment, it is still much quicker than during the period of the dollar peg, which implies that the development of a more liquid foreign exchange market is not fully hindered by the financial turbulences.

\subsection{Robustness Check}

\subsubsection{Conditional on de jure Capital Controls}

Government policies restricting capital flows are never perfect in that individuals and firms always find ways to circumvent regulations for higher returns available. Thus, even if the legal restrictions remain unchanged, the measure of de jure capital controls may not capture the degree or the effectiveness of their enforcement, which can change over time (Kose et al., 2009). Because capital control policies may change during the sample period, it is better to control this variable to check for their ineffectiveness. Specifically, the capital control relaxation of some extent allows a more open capital account and may reduce the yield differential or the threshold, while it does not mean a non-effective capital control. Alternative (de jure) capital control indices are constructed to represent the evolution of the policy and 
are widely used in empirical studies. ${ }^{4546}$ One incompatibility of these indices, let alone their intrinsic drawbacks when constructed, is that they are time-invariant during our sample period, whereas the degree of capital control appears not to be constant. ${ }^{47}$ Accordingly, we assume in this paper that China's overall de jure degree of capital control is constant during the sample period and estimate the de facto capital control intensity represented by the estimated threshold for each sub-period under this hypothesis.

\subsubsection{Conditional on Expectation of Forward Exchange Rate}

The NDF rates are determined outside China on the offshore market which is deeper and more liquid than the onshore market. They are the results of the interplay between market forces and may be interpreted as a proxy of market expectation for RMB's future exchange rate (Cheung and Qian, 2010). ${ }^{48}$ In this context, the NDF-implied interest yield differential also depends on exchange rate expectations. If the expectation reverses, the implied offshore RMB interest rate and consequently the yield differential measuring the degree of capital control may change equally without any change in capital control policy (see equation (6)). Following Cheung and Qian (2010), we calculate the deviation from CIP using the RMB deliverable forward rate of Chinese onshore market, which has developed recently and rapidly after the reform of exchange rate regime in 2005 but remains shallow and strictly regulated. The advantage of this onshore rate is that its pricing is mainly influenced by the CIP (see Peng et al., 2007). With this less expectation-driven rate, we re-estimate the outlined TAR model as a robustness check..$^{49}$

The calculated covered interest deviation shows a similar pattern as the yield differential derived with NDF, especially for the period of turmoil, but both the level and the volatility are significantly reduced in this case. What is entirely different is that, during the sub-period after the 2005 reform and before financial turmoil, this deviation fluctuated around zero. A much lower estimated threshold (43 versus 272 estimated with NDF) distinguishes two stationary regimes for which the deviations from CIP are mean reverting. More surprisingly, the adjustment to the threshold is more rapid for the non-arbitrage regime, with a HL of only 1.2 days relative to 5.2 days of the arbitrage regime. However, this last result is

\footnotetext{
${ }^{45}$ For example, using the capital control index compiled by Chan-Lee (2002) as proxy, Cheung et al. (2006) include the degree of financial account restrictions to explain the deviation from uncovered interest parity between China and some other economies; Cheung and Qian (2010) include a dummy variable to take into account the change of capital control policy when studying the deviation from the covered interest parity between China and the U.S..

${ }^{46}$ It captures the shift of China's policy bias from tightening to loosening and from primarily controlling outflow to controlling both inflows and outflows. It is assigned a value of +1 for the observations before September 2001, when China tightened capital outflow; a value 0 for the observations between September 2001 and October 2002, when it is deemed as a transition period; and a value -1 for the observations after October 2002, when Chinese authorities started to encourage or promote capital outflow.

${ }^{47}$ In Cheung and Qian (2010), no extra dummy variable that captures the timing of China's capital control policy changes has been introduced after October 2002; the financial openness index for China of Chinn and Ito (2008) is constant from 1993.

${ }^{48}$ The pricing of the RMB NDF is proved not tied to its financial fundamentals (Peng et al., 2007).

${ }^{49} \mathrm{We}$ estimate only for the second and the third sub-periods since this onshore market-based forward rate did not exist before the reform of 2005. Aforementioned statistical tests are applied to this deviation, with the results allowing us to estimate the TAR model. These results are not reported here because of limit of space, but available upon request.
} 
counterintuitive and is not easy to interpret. In contrast, the linear specification produces a HL of 3.6 days, which is in the neighborhood of that estimated with NDF series.

For the period of turmoil, the estimated threshold is about 83 basis points, almost double relative to the previous sub-period. However, the quicker adjustment pattern in the nonarbitrage regime during the first two sub-periods has been sustained until the period of crisis. Moreover, the adjustments to the threshold in both regimes have slowed correspondingly (with HL of 10.7 and 2.3 respectively). The linear estimation of HL shows a lower speed of adjustment to zero than its counterpart in the quiet sub-period (about 17 days). Estimated with NDF, the linear (TAR) HL is 10 days (4 days).

In summary, the use of the onshore forward rate of RMB (which is less influenced by the expectations of currency appreciation or depreciation) reduces both the level and the volatility of deviation (or yield differential) from CIP. ${ }^{50}$ It also decreases the thresholds that indicate the de facto degree of capital control. However, the threshold is found to increase during the period of financial turmoil and is similar to the result obtained using the NDF-based TAR model, which partly confirms the robustness of our conclusion. As for the threshold gap between the onshore forward-based and NDF-based estimations, it may be due to the understatement of the deviation from CIP and consequently the intensity of capital control by using onshore forward rate. In spite of the pricing based on CIP, the onshore forward market is shallow relative to the NDF market because of the "real demand principal" and restrictive regulations on participants (Peng et al., 2007). Therefore, the capital controls persist even if the deviation does not, as the onshore forward is less liquid and may be unrepresentative. Based on this reason, the results from the TAR model with the NDF series are still informative and robust. After all, because the onshore forward market develops and deepens, there may be some information transmission from the CIP-based onshore forward rate to the NDF rate. It makes the NDF rate not so much expectationdriven and still acceptable for measuring the yield differential of currencies.

\section{Concluding remarks}

This paper proposes an assessment of the effectiveness of the capital controls in China. Using a two-regime TAR model, it studies the RMB interest yield differential between the onshore rate and the NDF-implied offshore rate for the period from mid-2003 to the beginning of 2010. With the threshold and half-life (HL) estimated for each sub-period, we find that the de facto intensity of capital controls increases over time, as reflected by the rising threshold of arbitrage, even during the period of financial turbulence. When excessive profits appear, the time of adjustment toward the threshold measuring the intensity of capital controls and transaction costs is reduced after the abandonment of the dollar peg of RMB, as the force of arbitrage plays a more important role in a more liquid and developed forward market of foreign exchange. The eruption of the financial crisis did not fully interrupt this process; even it inflates the yield differential because of both increased liquidity risk and a US dollar

\footnotetext{
${ }^{50}$ As the market grows, banks increasingly price forwards and swaps based on the interest rate parity in recent periods. The derivatives market is increasingly driven by financial fundamentals (Peng et al., 2007).
} 
funding shortage. Moreover, a slightly lower speed of adjustment to the threshold implies that the capital controls are effective in this context.

The PBOC announced on June 192010 the abandonment of the dollar peg that it adopted as a "special measure" to deal with the period of financial turbulence and the re-switching to a managed floating regime with reference to a basket of currencies. This announcement confirms the end of the anticipation of a stable RMB-dollar rate by the market. If the Chinese monetary authority commits to implement this managed float regime, as it did from mid-2006 to mid-2008, more developed forward and derivatives markets as well as more open capital accounts seem needed and can thus facilitate the internationalization of the RMB. Because the option of lifting the capital controls to allow the full internationalization of the RMB is less possible (Cheung et al., 2010), the issue of how the implementation of the capital controls will be done is challenging and promising. 


\section{References}

Aliber, R. Z. (1973): "The Interest Rate Parity Theorem: A Reinterpretation," Journal of Political Economy, 81, 1451-59.

BABA, N. AND F. PACKer (2009): "Interpreting deviations from covered interest parity during the financial market turmoil of 2007-08," Journal of Banking and Finance, 33, 1953-1962.

Baba, N., F. Packer, And T. Nagano (2008): "The Spillover of Money Market Turbulence to FX and Cross-currency Swap Markets," BIS Quarterly Review, March, 73-86.

Bai, J. And P. Perron (1998): "Estimating and Testing Linear Models with Multiple Structural Changes," Econometrica, 66, 47-78.

Bec, F. And M. Ben SAlem (2004): "L'ajustement à seuil des processus cointégrés," Revue d'Économie Politique, 114, p. 467-488.

Bec, F., M. Ben Salem, and M. Carrasco (2004): "Tests for Unit-Root versus Threshold Specification With an Application to the Purchasing Power Parity Relationship," Journal of Business \& Economic Statistics, 22, 382-395.

Ben Salem, M. and C. Perraudin (2001): "Tests de linéarité, spécification et estimation de modèles à seuil : une analyse comparée des méthodes de Tsay et de Hansen," Economie et prévision, p. 157-176.

Branson, W. H. (1969): "The Minimum Covered Interest Differential Needed for International Arbitrage Activity," Journal of Political Economy, 77, 1028-35.

Chan-Lee, J. H. (2002): "Beyond Sequencing: What does a Risk Based Analysis of Core Institutions, Domestic Financial and Capital Account Liberalization Reveal About Systemic Risk in Asian Emerging Market Economies," ADB Institute Research Paper 46, ADB Institute.

Cheung, Y.-W., M. D. Chinn, And E. Fujil (2006): "The Chinese economies in global context: The integration process and its determinants," Journal of the Japanese and International Economies, 20, 128-153.

Cheung, Y.-W., G. Ma, and R. N. McCauley (2010): "Renminbising China's Foreign Assets," CESifo Working Paper Series 3009, CESifo Group Munich.

Cheung, Y.-W. And X. QIAn (2010): "Deviations from Covered Interest Parity: The Case of China," Working paper, SUNY Buffalo State College.

Chinn, M. D. And H. Ito (2008): "A New Measure of Financial Openness," Journal of Comparative Policy Analysis: Research and Practice, 10, 309-322.

Chol, C.-Y. And Y.-K. MoH (2007): "How useful are tests for unit-root in distinguishing unit-root processes from stationary but non-linear processes," Econometric Journal, 10, $82-112$.

Dooley, M. P. And P. Isard (1980): "Capital Controls, Political Risk, and Deviations from Interest-Rate Parity," Journal of Political Economy, 88, 370-84.

Einzig, P. (1937): The Theory of Forward Exchange, London: Macmillan. 
Enders, W. And C. W. J. Granger (1998): "Unit-Root Tests and Asymmetric Adjustment with an Example Using the Term Structure of Interest Rates," Journal of Business 83 Economic Statistics, 16, 304-11.

Feldstein, M. And C. Horioka (1980): "Domestic Saving and International Capital Flows," Economic Journal, 90, 314-29.

Fong, W.-M., G. Valente, and J. K. Fung (2010): "Covered interest arbitrage profits: The role of liquidity and credit risk," Journal of Banking \& Finance, 34, 1098-1107.

Frankel, J. A. (1992): "Measuring International Capital Mobility: A Review," American Economic Review, 82, 197-202.

(1993): "Quantifying International Capital Mobility in The 1980s," in International Finance: Contemporary Issues, ed. by K. D. Dilip, Routeledge, 27-53.

Frenkel, J. A. (1973): "Elasticities and the Interest Parity Theory," Journal of Political Economy, 81, 741-47.

Frenkel, J. A. And R. M. Levich (1975): "Covered Interest Arbitrage: Unexploited Profits?" Journal of Political Economy, 83, 325-38.

(1977): "Transaction Costs and Interest Arbitrage: Tranquil versus Turbulent Periods," Journal of Political Economy, 85, 1209-26.

Fung, H.-G., W. K. Leung, And J. Zhu (2004): "Nondeliverable forward market for Chinese RMB: A first look," China Economic Review, 15, 348-352.

Glosten, L. R., R. Jagannathan, and D. E. Runkle (1993): "On the Relation between the Expected Value and the Volatility of the Nominal Excess Return on Stocks," The Journal of Finance, 48, 1779-1801.

Goldstein, M. And N. Lardy (2006): "China's Exchange Rate Policy Dilemma," American Economic Review, 96, 422-426.

Hansen, B. E. (1996): "Inference When a Nuisance Parameter Is Not Identified under the Null Hypothesis," Econometrica, 64, 413-30.

- (1999): "Testing for Linearity," Journal of Economic Surveys, 13, 551-76.

Harvey, D. I. And S. J. Leybourne (2007): "Testing for time series linearity," Econometrics Journal, 10, 149-165.

Holmes, M. AND Y. Wu (1997): "Capital controls and covered interest parity in the EU: Evidence from a panel-data unit root test," Review of World Economics (Weltwirtschaftliches Archiv), 133, 76-89.

Holmes, M. J. (2001): "New Evidence on Real Exchange Rate Stationarity and Purchasing Power Parity in Less Developed Countries," Journal of Macroeconomics, 23, 601-614.

Hutchison, M., J. Kendall, G. K. Pasricha, And N. Singh (2009): "Indian Capital Control Liberalization: Evidence from NDF Markets," MPRA Paper 13630, University Library of Munich, Germany.

IMF (2000): "Capital Controls: Country Experiences with Their Use and Liberalization," IMF Occasional Paper, 190. 
Iто, T. (1987): "Capital Controls and Covered Interest Parity," NBER Working Papers 1187, National Bureau of Economic Research, Inc.

Keynes, J. M. (1923): A Tract on Monetary Reform, London: Macmillan.

Kose, M. A., E. Prasad, K. Rogoff, and S.-J. Wei (2009): "Financial Globalization: A Reappraisal," IMF Staff Papers, 56, 8-62.

Lee, J. And M. C. Strazicich (2003): "Minimum Lagrange Multiplier Unit Root Test with Two Structural Breaks," The Review of Economics and Statistics, 85, 1082-1089.

Levy Yeyati, E., S. L. Schmukler, And N. Van Horen (2009): "International financial integration through the law of one price: The role of liquidity and capital controls," Journal of Financial Intermediation, 18, 432 - 463.

Ma, G., C. Ho, and R. N. McCauley (2004): "The markets for non-deliverable forwards in Asian currencies," BIS Quarterly Review.

Ma, G. And R. McCauley (2008): "Efficacy Of China'S Capital Controls: Evidence From Price And Flow Data," Pacific Economic Review, 13, 104-123.

(2010): "The evolving renminbi regime and implications for Asian currency stability," BIS Working Papers 321, Bank for International Settlements.

MacDonald, R. (2007): Exchange Rate Economics: Theories and Evidence, UK: Routledge, 2 ed.

Mignon, V. And G. Dufrénot (2004): "Modeling the French Consumption Function Using SETAR Models," Economics Bulletin, 3, 1-16.

NG, S. And P. Perron (2001): "LAG Length Selection and the Construction of Unit Root Tests with Good Size and Power," Econometrica, 69, 1519-1554.

Obstfeld, M. And A. M. TAYlor (1997): "Nonlinear Aspects of Goods-Market Arbitrage and Adjustment: Heckscher's Commodity Points Revisited," Journal of the Japanese and International Economies, 11, 441-479.

OtAni, I. AND S. TiWARI (1981): "Capital controls and interest rate parity: The Japanese experience, 1978-81," IMF Staff Papers, 28, 793-815.

PARK, J. Y. AND M. Shintani (2005): "Testing for a Unit Root against Transitional Autoregressive Models," Working Papers 05010, Department of Economics, Vanderbilt University.

Peel, D. A. And M. P. Taylor (2002): "Covered Interest Rate Arbitrage in the Interwar Period and the Keynes-Einzig Conjecture," Journal of Money, Credit and Banking, 34, $51-75$.

Peng, W., C. Shu, And R. Yip (2007): "Renminbi Derivatives: Recent Development and Issues," China \&3 World Economy, 15, 1-17.

Petrucelli, J. And S. Woolford (1984): "A threshold AR(1) model," Journal of Applied Probability, 21, 520-33.

Prachowny, M. F. J. (1970): "A Note on Interest Parity and the Supply of Arbitrage Funds," Journal of Political Economy, 78, pp. 540-45. 
Shah, A., A. Zeileis, And I. Patnaik (2005): "What is the New Chinese Currency Regime?" Research Report SeriesDepartment of Statistics and Mathematics 23, Department of Statistics and Mathematics, WU Vienna University of Economics and Business, Vienna.

TAYlor, J. B. And J. C. Williams (2008a): "A Black Swan in the Money Market," NBER Working Papers 13943, National Bureau of Economic Research, Inc.

- (2008b): "Further Results on a Black Swan in the Money Market," Discussion Papers 07-046, Stanford Instititute for Economic Policy Research.

TAYlor, M. P. (1987): "Covered Interest Parity: A High-Frequency, High-Quality Data Study," Economica, 54, 429-38. 376-91.

(1989): "Covered Interest Arbitrage and Market Turbulence," Economic Journal, 99,

TAYlor, M. P. And E. TChernykh-Branson (2004): "Asymmetric Arbitrage and Default Premiums Between the U.S. and Russian Financial Markets," IMF Staff Papers, 51, 257275.

Tong, H. (1978): "On a threshold model," in Pattern recognition and signal processing, ed. by C. Chen, Netherlands: Sijthoff \& Noordhoff, 575-586.

(1983): Threshold models in non-linear time series analysis, Lecture notes in statistics, NO.21, New York: Springer-Verlag.

Tong, H. And K. S. Lim (1980): "Threshold Autoregression, Limit Cycles and Cyclical Data," Journal of the Royal Statistical Society. Series B (Methodological), 42, 245-292.

TSAY, R. S. (1989): "Testing and modeling threshold autoregressive processes," Journal of the American Statistical Association, 84, 231-240.

XU, K.-L. (2008): "Bootstrapping Autoregression under Non-stationary Volatility," Econometrics Journal, 11, 1-26.

Zhang, X. (2003): "Capital Account Management and Its Outlook in China," BIS Papers No. 15, Bank forInternational Settlements. 

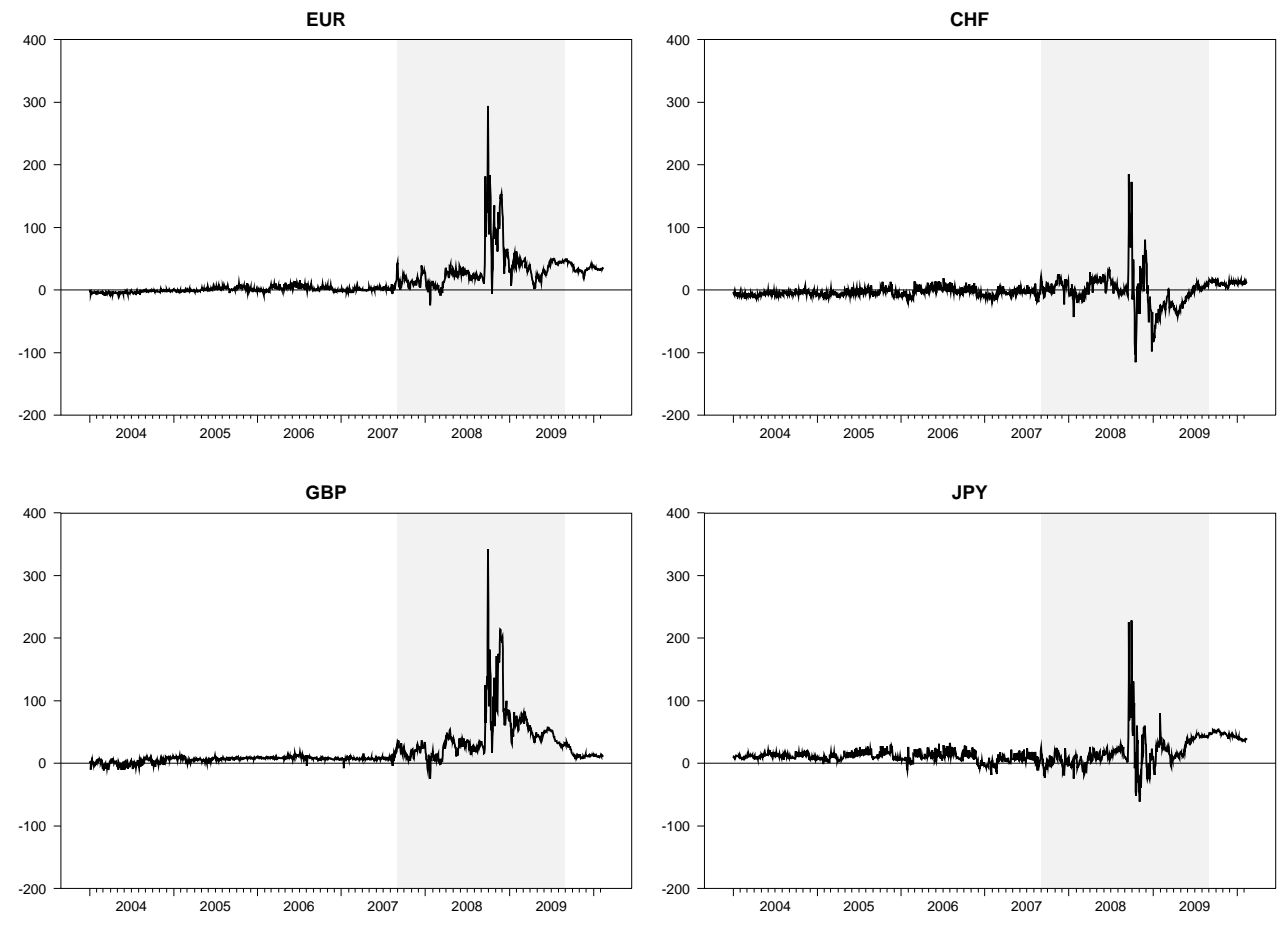

Source: Datastream WM/Reuters and author's calculation (daily data)

Figure 1: Covered differentials of major currencies/USD (Basis point)
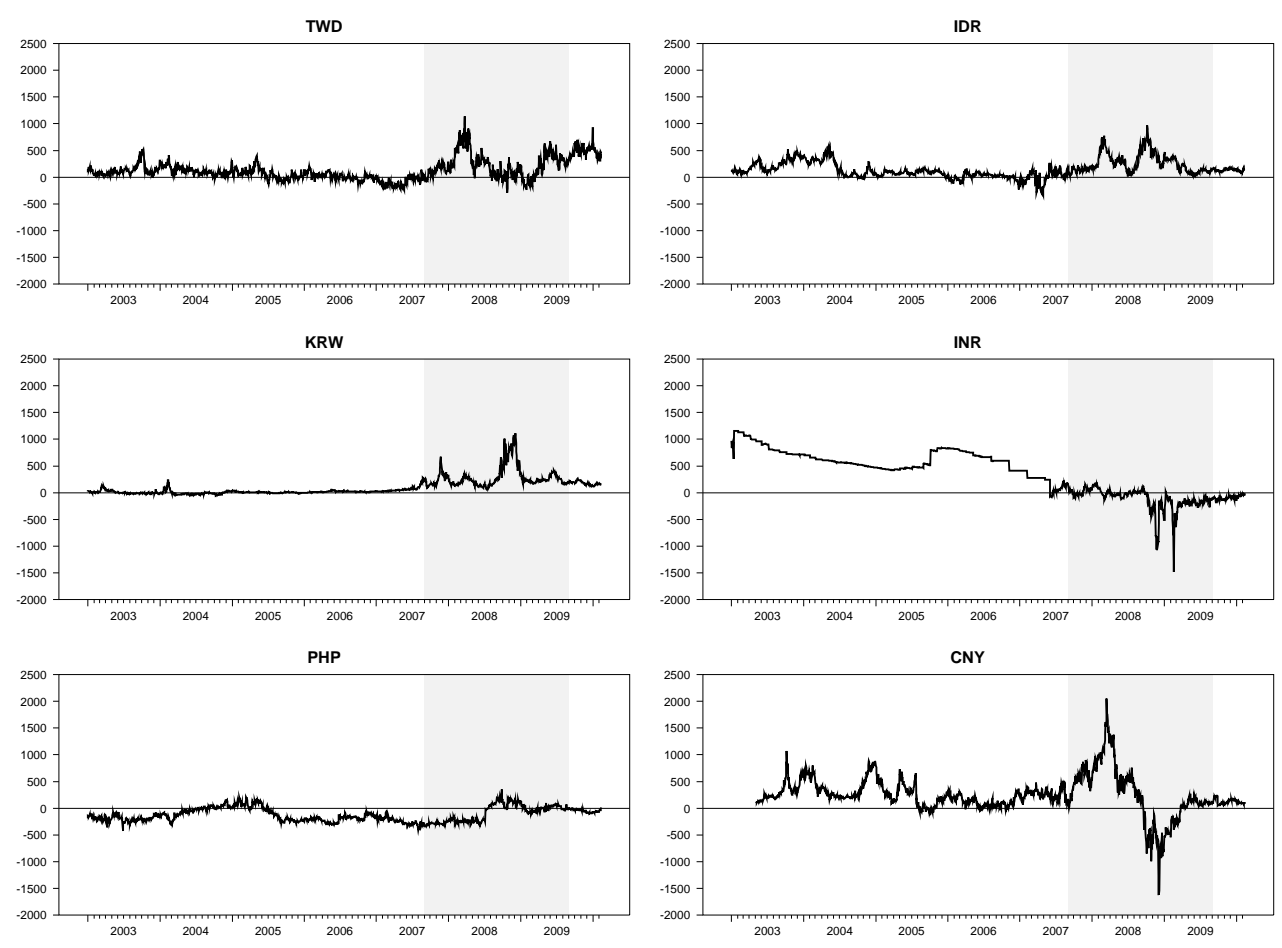

Source: Datastream WM/Reuters and author's calculation (daily data)

Figure 2: Covered differentials of Asian currencies/USD with NDF market (Basis points) 


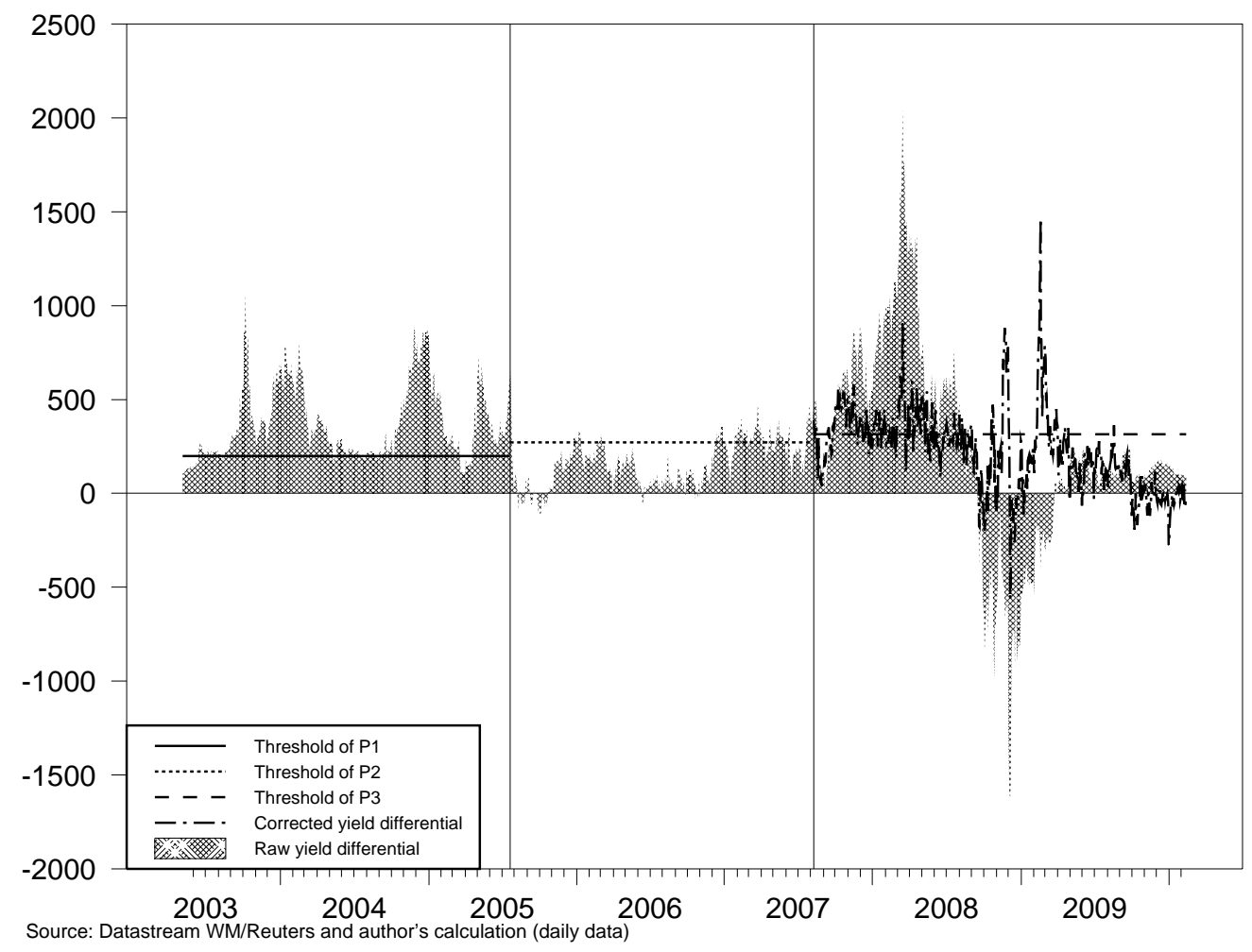

Figure 3: Covered interest yield differentials of RMB (Basis points)
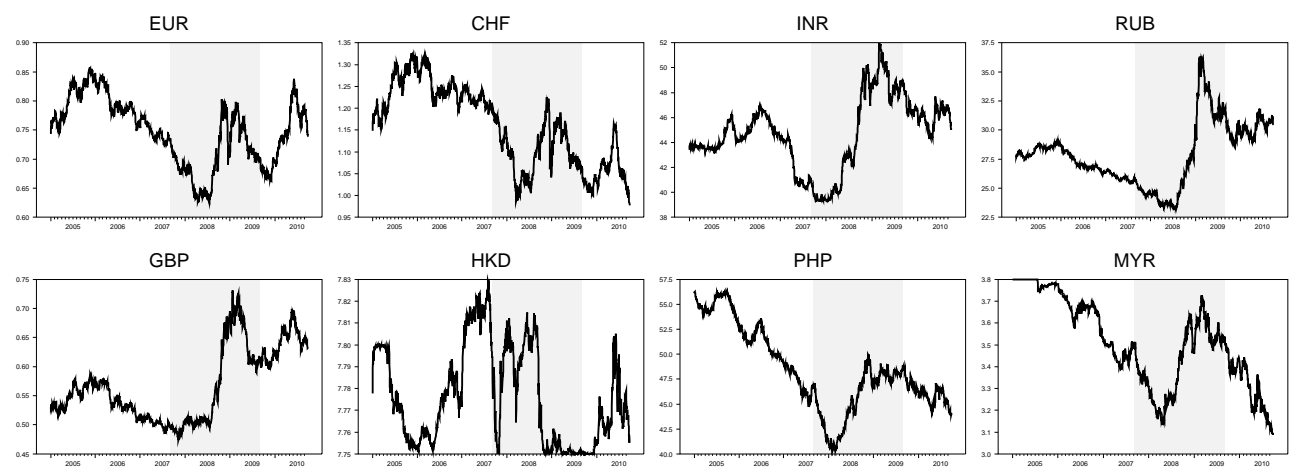

PHP
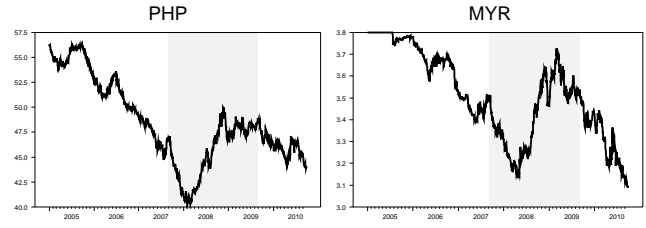

CAD

SGD
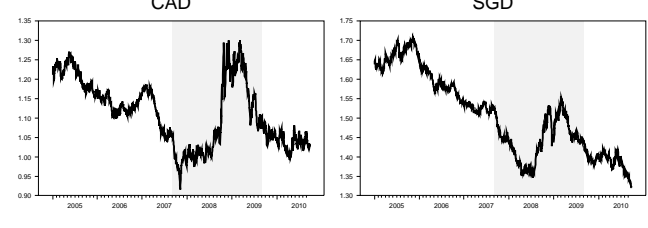

KRW

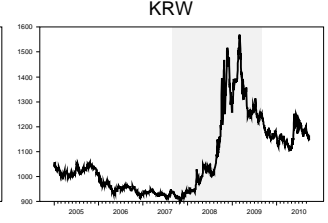

THB

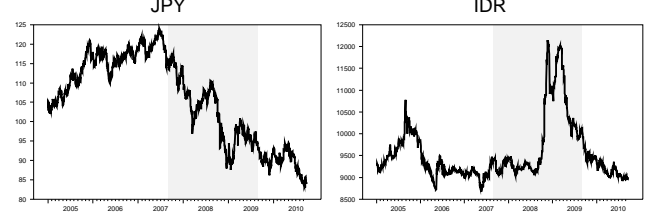

TWD

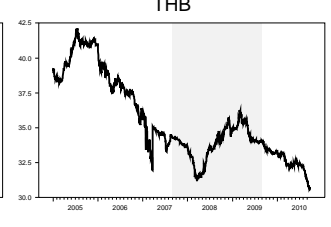

CNY
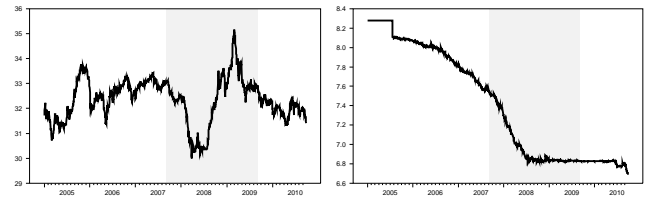

Source: Datastream WM/Reuters (daily data)

Figure 4: Spot rates 

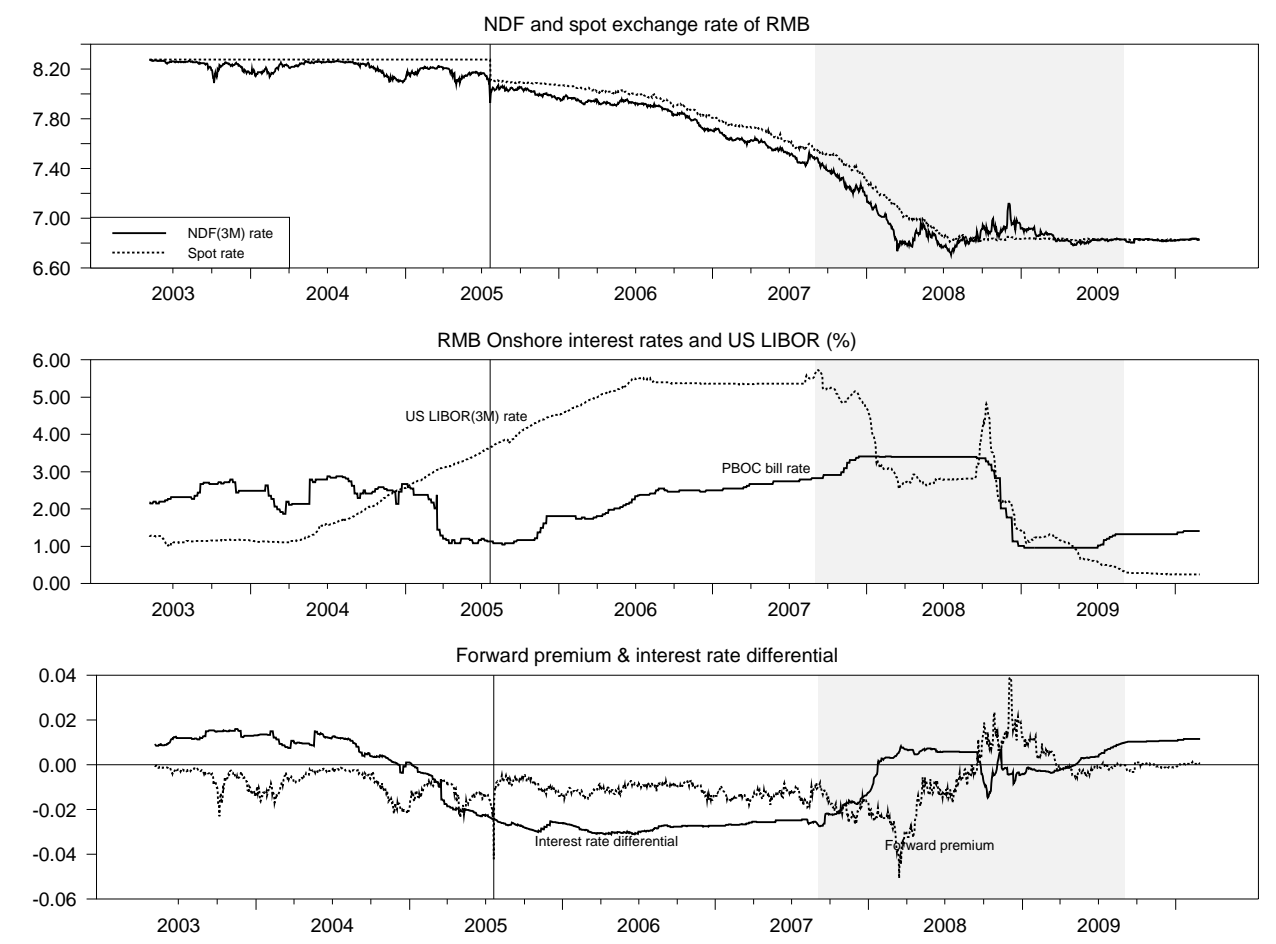

Source: Datastream WM/Reuters and author's calculation (daily data)

Figure 5: Components of CIP 
Table 1: Summary statistics of RMB yield differentials (3M-maturity)

\begin{tabular}{lccccc}
\hline Period & Mean & Std. Dev. & Min. & Max. & Obs. \\
\hline Whole & 249.156 & 351.886 & -1618.882 & 2052.697 & 1769 \\
$1 s t$ & 366.790 & 192.988 & 100.289 & 1072.327 & 577 \\
$2 n d$ & 154.455 & 123.653 & -108.764 & 655.957 & 535 \\
$3 r d$ & 222.961 & 518.072 & -1618.882 & 2052.697 & 657 \\
$3 r d^{c}$ & 222.961 & 215.792 & -567.187 & 1464.838 & 657 \\
\hline
\end{tabular}

Note: ${ }^{c}$ denotes that the data used for this period are corrected.

Table 2: Stationarity tests

\begin{tabular}{lllrlrr}
\hline \multirow{2}{*}{ Period } & \multicolumn{2}{c}{ N-P ADF model } & & \multicolumn{2}{c}{ M-TAR Model } \\
\cline { 2 - 4 } & MZa & MZt & $\hat{k}$ & & $\phi^{*}$ \\
\hline Whole & $-14.8024^{* *}$ & $-2.7204^{* *}$ & 12 & & $4.3266^{*}$ & 12 \\
$1 s t$ & -5.0047 & -1.4061 & 5 & $5.5520^{* *}$ & 8 \\
$2 n d$ & -1.0801 & -0.7262 & 8 & $4.8262^{* \mathrm{~b}}$ & 1 \\
$3 r d$ & -3.7493 & -1.3353 & 12 & 1.3486 & 12 \\
$3 r d^{c}$ & $-12.1675^{* *}$ & $-2.4665^{* *}$ & 3 & $6.7896^{* *}$ & 2 \\
\hline
\end{tabular}

${ }^{\mathrm{a}}$ For Ng-Perron test, only intercept is included in the model.

${ }^{\mathrm{b}}$ M-TAR test is run on the demeaned series. $\hat{k}$ is the number of lags that is auto-selected by minimizing the AIC criteria. To ensure the estimation run over the same sample for each sub-period, we fix the number of first usable observation as the sum of k-max, the times of first difference of dependent variable and 1.

${ }^{\mathrm{c}}$ When we discard the first ten points of this period (because of their abnormal behavior due to the beginning period effect of the new exchange rate regime), the power of the test is increased to $5 \%$.

$\mathrm{d} *, * *$, and $* * *$ denote significance at the $10 \%, 5 \%$, and $1 \%$ levels, respectively.

Table 3: LS unit root test with structural breaks

\begin{tabular}{lcccc}
\hline & $\hat{k}$ & $T_{B}$ & Test statistic & Critical value Break points \\
\hline Level & 8 & $2005: 08: 15,2006: 07: 26$ & -4.1634 & $\lambda=(0.3,0.5)$ \\
$1^{\text {st }}$-difference & 6 & $2006: 07: 26,2008: 09: 15$ & -3.0095 & $\lambda=(0.5,0.8)$ \\
\hline
\end{tabular}

Notes: $\hat{k}$ is the optimal number of lagged first-differenced terms included in the unit root test to correct for serial correlation. $\hat{T}_{B}$ denotes the estimated break points. Critical values are shown below for the two-break minimum LM unit root test with linear trend (Model C) at the $1 \%, 5 \%$, and $10 \%$ levels for a sample of size $T=100$, respectively, depending on the location of the breaks $\lambda=\left(T_{B 1} / T, T_{B 2} / T\right)$. The critical values for LM test with breaks come from Table 2 in Lee and Strazicich $(2003) .{ }^{*},{ }^{* *}$, and ${ }^{* * *}$ denote significance at the $10 \%, 5 \%$, and $1 \%$ levels, respectively.

\begin{tabular}{llll}
\hline Break Points Timing & \multicolumn{3}{c}{ Critical Values } \\
\cline { 2 - 4 }$\lambda=\left(T_{B 1} / T, T_{B 2} / T\right)$ & $1 \%$ & $5 \%$ & $10 \%$ \\
\hline$\lambda=(0.2,0.4)$ & -6.16 & -5.59 & -5.27 \\
$\lambda=(0.2,0.6)$ & -6.41 & -5.74 & -5.32 \\
$\lambda=(0.2,0.8)$ & -6.33 & -5.71 & -5.33 \\
$\lambda=(0.4,0.6)$ & -6.45 & -5.67 & -5.31 \\
$\lambda=(0.4,0.8)$ & -6.42 & -5.65 & -5.32 \\
$\lambda=(0.6,0.8)$ & -6.32 & -5.73 & -5.32 \\
\hline
\end{tabular}


Table 4: Autoregressive model with asymmetric GARCH effect

\begin{tabular}{|c|c|c|c|c|c|c|c|c|c|c|}
\hline \multirow{2}{*}{ Period } & \multicolumn{8}{|c|}{ Augmented $\operatorname{AR}(1)$ with Asymmetric $\operatorname{GARCH}(1,1)$} & \multicolumn{2}{|c|}{ Ljung-Box Q-stat. } \\
\hline & $C_{0}$ & $\rho$ & HL & $\mathrm{k}$ & $\alpha_{0}$ & $\alpha_{1}$ & $\lambda_{1}$ & $\gamma_{1}$ & SR & SSR \\
\hline \multirow[t]{2}{*}{$1 s t$} & 9.211 & -0.033 & 20.66 & 0 & 28.349 & 0.479 & 0.742 & -0.329 & $0.34[10]$ & $0.17[10]$ \\
\hline & $(0.000)$ & $(0.002)$ & & & $(0.006)$ & $(0.000)$ & $(0.000)$ & $(0.000)$ & $0.87[20]$ & $0.21[20]$ \\
\hline \multirow[t]{2}{*}{$2 n d$} & 8.054 & -0.049 & 13.80 & 1 & 347.656 & 0.180 & 0.689 & -0.149 & $0.21[10]$ & $0.19[10]$ \\
\hline & $(0.005)$ & $(0.001)$ & & & $(0.006)$ & $(0.006)$ & $(0.000)$ & $(0.026)$ & $0.21[20]$ & $0.28[20]$ \\
\hline \multirow[t]{2}{*}{$3 r d$} & 0 & -0.015 & 45.86 & 1 & -0.865 & 0.137 & 0.915 & -0.085 & $0.57[10]$ & $0.99[10]$ \\
\hline & & $(0.015)$ & & & $(0.734)$ & $(0.000)$ & $(0.000)$ & $(0.002)$ & $0.89[20]$ & $0.997[20]$ \\
\hline \multirow[t]{2}{*}{$3 r d^{c}$} & 15.265 & -0.069 & 9.69 & 1 & 706.645 & 0.298 & 0.707 & -0.160 & $0.74[10]$ & $0.80[10]$ \\
\hline & $(0.000)$ & $(0.000)$ & & & $(0.003)$ & $(0.000)$ & $(0.000)$ & $(0.015)$ & $0.48[20]$ & $0.98[20]$ \\
\hline \multirow{2}{*}{\multicolumn{3}{|c|}{ Estimated equation: }} & \multirow{2}{*}{\multicolumn{5}{|c|}{$\begin{array}{l}\Delta y_{t}=C_{0}+\rho y_{t-1}+\sum_{j=1}^{k} \phi_{j} \Delta y_{t-j}+\epsilon_{t} \\
\sigma_{t}^{2}=\alpha_{0}+\alpha_{j} \epsilon_{t-1}^{2}+\lambda_{j} \sigma_{t-1}^{2}+\gamma_{1} \epsilon_{t-1}^{2} I_{t-1}\end{array}$}} & \multicolumn{3}{|c|}{$I_{t-1}=1$ if $\epsilon_{t-1}<0$} \\
\hline & & & & & & & & \multicolumn{3}{|c|}{$I_{t-1}=0$ otherwise } \\
\hline
\end{tabular}

Notes: The figures in squared brackets denote the number of correlations for which the Q-statistic is applied to the residuals. SR denotes standardized residual and SSR squared standardized residual. HF is the half-life calculated as $\ln (0.5) / \ln \left(1+\rho^{\text {out }}\right)$. ${ }^{c}$ denotes the data used for this period is corrected ones. There is no augmented term in the mean equation when $k=0$.

Table 5: Non-linearity tests

\begin{tabular}{|c|c|c|c|c|}
\hline \multirow{2}{*}{ Period } & \multirow{2}{*}{$\operatorname{Lag}(\mathrm{n})$} & Tsay's TAR-F & Hansen's sup-LM & LLR \\
\hline & & \multicolumn{3}{|c|}{$d=1$} \\
\hline 1 st & $1,4,6$ & $\begin{array}{l}1.544 \\
(0.188)\end{array}$ & $\begin{array}{l}26.874^{* * *} \\
(0.004)\end{array}$ & $\begin{array}{l}9.511^{* *} \\
(0.047)\end{array}$ \\
\hline 2nd & 1,2 & $\begin{array}{l}0.366 \\
(0.777)\end{array}$ & $\begin{array}{l}11.966 \\
(0.189)\end{array}$ & $\begin{array}{l}4.190 \\
(0.433)\end{array}$ \\
\hline $3 n d^{c}$ & 1 & $\begin{array}{l}3.559^{* *} \\
(0.029)\end{array}$ & $\begin{array}{l}9.779 \\
(0.123)\end{array}$ & $\begin{array}{l}4.169 \\
(0.314)\end{array}$ \\
\hline
\end{tabular}

Notes: AR models are fitted with different lags for removing any serial correlation in the data, then TARF and sup-LM tests are applied to the residual series of the model. For sup-LM test, heteroscedasticity consistent estimates are used for calculating the standard errors; bootstrapped p-value (with 2000 draws) are calculated and showed in parenthesis; $d$ denotes the delay parameter. ${ }^{*},{ }^{*}$, and ${ }^{* * *}$ denote significance at the $10 \%, 5 \%$, and $1 \%$ levels, respectively. The fractiles of LLR test statistics are tabulated as follows based on 600 simulations.

\begin{tabular}{lrrr}
\hline Fractiles & P1 & P2 & P3 \\
\hline Minimum & 0.406 & 0.787 & 0.104 \\
01-\%ile & 0.686 & 0.977 & 0.470 \\
05-\%ile & 1.216 & 1.496 & 0.896 \\
10-\%ile & 1.519 & 1.813 & 1.174 \\
25-\%ile & 2.453 & 2.692 & 1.804 \\
Median & 3.871 & 3.787 & 2.975 \\
75-\%ile & 5.989 & 5.647 & 4.794 \\
90-\%ile & 8.058 & 7.748 & 7.035 \\
95-\%ile & 9.371 & 9.250 & 8.411 \\
99-\%ile & 13.675 & 13.002 & 11.051 \\
Maximum & 19.824 & 36.390 & 12.750 \\
\hline
\end{tabular}




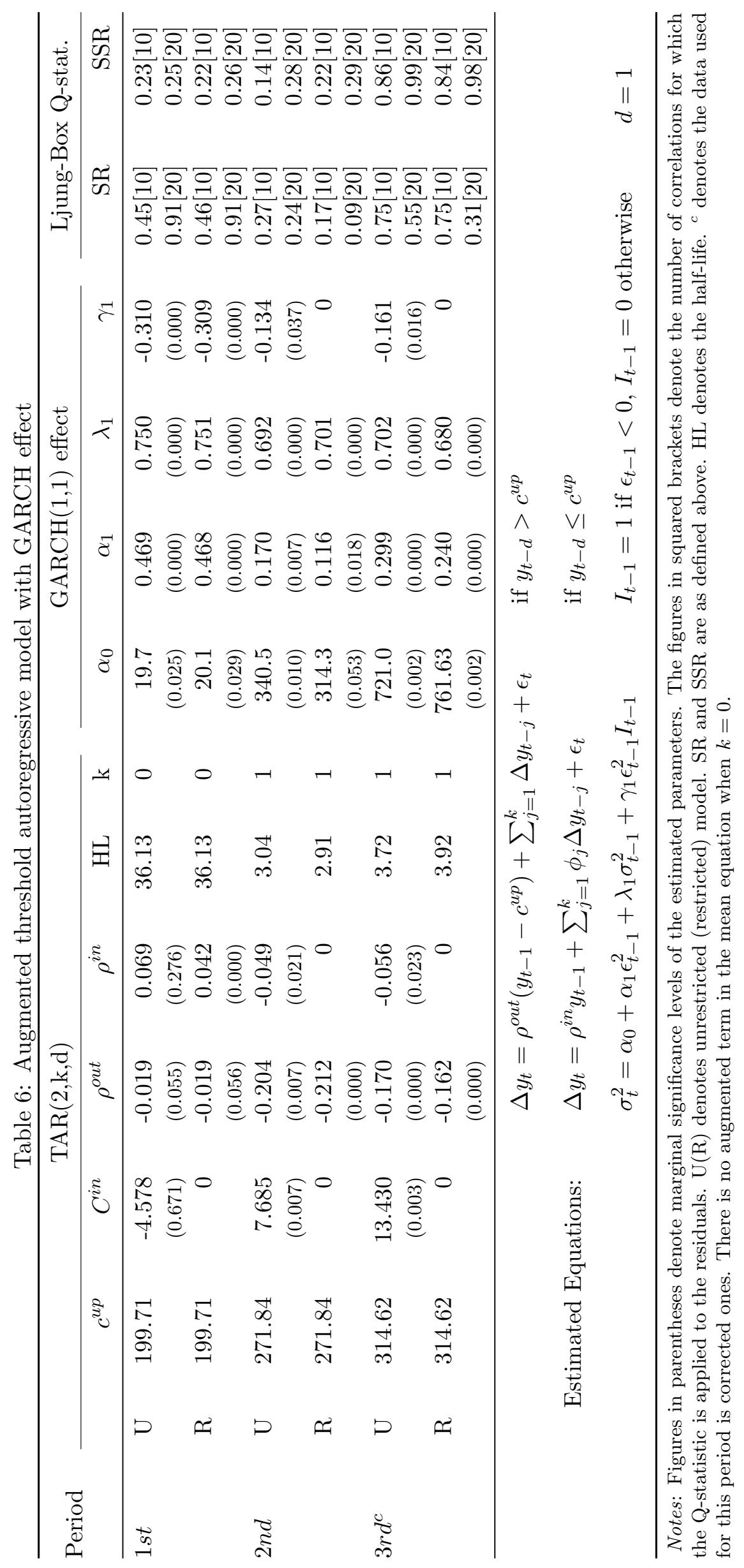


Table 7: Summary statistics of yield differentials for period of crisis (Asian NDF markets)

\begin{tabular}{ccccc}
\hline Variable & Mean & Std. Dev. & Min. & Max. \\
\hline hkd & 6.405 & 12.794 & -65.785 & 78.817 \\
twd & 266.883 & 240.915 & -290.743 & 1136.227 \\
krw & 268.177 & 182.717 & 60.435 & 1116.773 \\
php & -81.870 & 148.875 & -361.663 & 353.558 \\
idr & 237.304 & 173.773 & -42.071 & 965.985 \\
inr & -103.595 & 190.196 & -1477.311 & 225.5 \\
cny & 222.961 & 518.072 & -1618.882 & 2052.697 \\
\hline \multicolumn{2}{r}{} & & & \\
\end{tabular}

Table 8: Factor analysis with principal component approach (1)

\begin{tabular}{|c|c|c|c|c|}
\hline Factor & Eigenvalue & Difference & Proportion & Cumulative \\
\hline Factor 1 & 2.80195 & 1.72728 & 0.4670 & 0.4670 \\
\hline Factor2 & 1.07467 & 0.15833 & 0.1791 & 0.6461 \\
\hline Factor3 & 0.91634 & 0.33062 & 0.1527 & 0.7988 \\
\hline Factor 4 & 0.58572 & 0.13863 & 0.0976 & 0.8964 \\
\hline Factor5 & 0.44709 & 0.27286 & 0.0745 & 0.9710 \\
\hline Factor6 & 0.17423 & 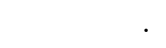 & 0.0290 & 1.0000 \\
\hline Variable & Factor1 & Factor 2 & Uniqueness & \\
\hline twd & 0.5044 & 0.3483 & 0.6243 & \\
\hline krw & -0.7440 & 0.3594 & 0.3174 & \\
\hline php & -0.7525 & -0.0886 & 0.4258 & \\
\hline idr & -0.3556 & 0.8333 & 0.1792 & \\
\hline inr & 0.7347 & 0.0234 & 0.4596 & \\
\hline cny & 0.8726 & 0.3486 & 0.1170 & \\
\hline
\end{tabular}

Notes: China mainland (CNY), Indonesia (IDR), India (INR), Philippines (PHP), South Korea (KRW) and Taiwan (TWD), with the abbreviation of their currency in parenthesis.

Table 9: Factor analysis with principal component approach (2)

\begin{tabular}{lrrrr}
\hline Factor & Eigenvalue & Difference & Proportion & Cumulative \\
\hline Factor1 & $\mathbf{1 . 8 6 1 6 0}$ & 1.03497 & 0.6205 & 0.6205 \\
Factor2 & 0.82663 & 0.51485 & 0.2755 & 0.8961 \\
Factor3 & 0.31178 & $\cdot$ & 0.1039 & 1.0000 \\
\hline Variable & Factor1 & Uniqueness & \\
\hline twd & 0.7035 & 0.5050 & \\
inr & 0.7349 & 0.4599 & & \\
cny & 0.9091 & 0.1735 & & \\
\hline
\end{tabular}

